\title{
Analysis for the ARIANE GU3 sample: nuclide inventory and decay heat
}

\author{
Dimitri Rochman ${ }^{1, *}$, Alexander Vasiliev $^{1}$, Hakim Ferroukhi ${ }^{1}$, Mathieu Hursin ${ }^{1}$, Raphaelle Ichou ${ }^{2}$, \\ Julien Taforeau ${ }^{2}$, and Teodosi Simeonov ${ }^{3}$ \\ ${ }^{1}$ Reactor Physics and Thermal hydraulic Laboratory, Paul Scherrer Institut, Villigen, Switzerland \\ ${ }^{2}$ Laboratoire de Neutronique, Institut de Radioprotection et de Sûreté Nucléaire, Fontenay-aux-Roses, France \\ ${ }^{3}$ Studsvik Scandpower, Inc., Newton, MA, USA
}

Received: 20 May 2021 / Received in final form: 2 August 2021 / Accepted: 10 August 2021

\begin{abstract}
This study presents an analysis of the ARIANE GU3 sample, in terms of nuclide inventory, as well as sample rod and assembly decay heat. The validation of a number of CASMO5 and library versions are performed with regards to the measured nuclide inventory, taking into account two dimensional lattice simulations. Uncertainties due to various sources (nuclear data, operating conditions and manufacturing tolerances) are also provided, and are combined with biases into expanded uncertainties. This study is similar to a previous one on the GU1 sample and fit in the framework of code validation, as well as in the estimation of code predictive power for spent fuel characterization.
\end{abstract}

\section{Introduction}

Nuclide inventory, as well as decay heat, are two important quantities for the characterization of spent nuclear fuel (SNF). Up to now, they are seldom measured given the large amount of SNF worldwide, and the reliance on simulation is essential for obtaining best-estimate values of these quantities. Moreover, the estimation of the source term in case of a hypothetical severe accident is of major importance, and the isotopic concentration for a large number of nuclides is highly relevant. These two aspects of the inventory for short and long periods of time after shutdown often involve different nuclides, which can hardly be measured. Consequently, the validation of the simulation codes (transport, depletion, activation) and their associated nuclear data libraries is a necessary step in order to establish their predictive power (range of applicability, uncertainties and biases).

The present study contributes to such validation efforts for the CASMO5 transport code [1-4]. The calculated nuclide inventory for the relocated Post Irradiation Examination sample GU3 from the ARIANE program [5] will be presented and compared to measurements, and calculated uncertainties as well as biases will be proposed. One particularity of the present study consists of using the same simulation input files with five code versions and six nuclear data libraries. This allows to estimate the spread due to code versions, as well as due to nuclear data libraries, which might be covered by calculated

\footnotetext{
*e-mail: dimitri-alexandre.rochman@psi.ch
}

uncertainties from input variations. Also, an attempt to link such nuclide predictive power to calculated (and not measured) decay heat will be established in the last part of this study.

Within this framework, this GU3 analysis is similar to the one for the ARIANE GU1 sample study [6]. Both analytical work are based on the same approach, using the same nuclear data, simulation tools, and assumptions for the uncertainties on operating conditions and manufacturing tolerances. This allows a direct comparison for the results from both samples, taking into account that the main differences between the Pressurized Water Reactor (PWR) $\mathrm{UO}_{2}$ GU1 and GU3 samples are the burnup values (about 59 and $52 \mathrm{MWd} / \mathrm{kgU}$, respectively) and the initial $\mathrm{UO}_{2}$ enrichments (3.5\% and $4.1 \%$, respectively).

This study is also providing an additional case for the European Horizon 2020 project EURAD project, dedicated to "spent fuel characterization and its evolution until disposal" in Work Package 8 [7]. The sample GU3 is also of interest as it was selected by the OECD Working Party on Nuclear Criticality Safety (WPNCS) subgroup 7 for sensitivity and uncertainty analysis. The present study will therefore provide additional results within these international efforts.

In the following, the characteristics of the GU3 sample and its irradiation conditions are presented, followed by concise recalls of the simulation tools (see Ref. [6] for more details). Finally, results in terms of $\mathrm{C} / \mathrm{E}-1$ (C and $\mathrm{E}$ being the calculated and measured quantities) and $\Delta \mathrm{C}$ (uncertainties being one standard deviation, or $1 \sigma$ ) will be presented for nuclide inventory, followed by the 

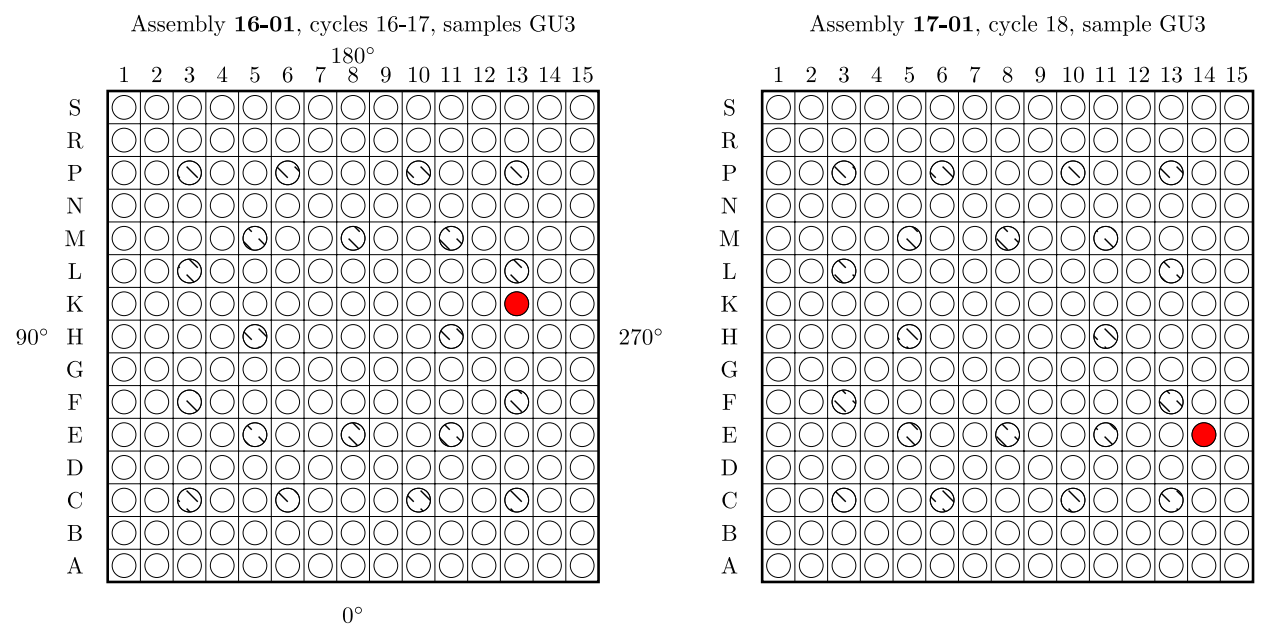

Fig. 1. Radial locations of the rod containing the GU3 sample in both assemblies (in red), before and after relocation (respectively left and right figures).

calculation of decay heat and its uncertainties. An estimation of the decay heat biases will be proposed, based on the nuclide inventory prediction. For the sake of simplification, quantities known as "expanded uncertainties" will be provided for both the calculated nuclide inventory and decay heat, combining biases and uncertainties from input variations. As many tabulated values are included in this study, they are separated from the main text and presented in appendices from Tables A.1-B.8.

\section{The GU3 sample}

The GU3 sample is one of the samples from the ARIANE program [5]. It is made of $\mathrm{UO}_{2}$ fuel with an enrichment of $4.1 \%$ in ${ }^{235} \mathrm{U}$ and is part of a $15 \times 15$ fuel PWR assembly. This particular sample was irradiated at the Gösgen power plant for three consecutive cycles: 16,17 and 18 . It was located in the same assembly for the two first cycles (assembly 16-01, with an average segment burnup of $38 \mathrm{MWd} / \mathrm{kgU}$ at the end of the second cycle), and then relocated in a different assembly for the last cycle (assembly 17-01, rod E14), see Figure 1 for an overview of the sample location within the assemblies. The assembly 17-01 was already irradiated prior receiving the rod containing the GU3 sample for one cycle and reached an segment burnup of about $20 \mathrm{MWd} / \mathrm{kgU}$ before receiving the relocated rod. The sample was located in a vertical location not close to a spacer. As observed in this figure, the location of GU3 is relatively close to the assembly side. Additionally, the rod relocation imposes GU3 to a heterogeneous environment over the full irradiation period. The locations of the assemblies containing GU3 in the full core of Gösgen are presented in Figure 2.

This figure illustrates the heterogeneous environment around the hosting assemblies, but preliminary studies taking into account the full core conditions (similar to the GU1 study) have shown that the impact is not statistically significant on the sample nuclide inventory. When taking into account realistic surrounding assemblies, the segment burnup distribution is not symmetric anymore, and a number of nuclide concentrations is changing, especially ${ }^{242 m} \mathrm{Am},{ }^{242,243} \mathrm{Cm}$ and to some extent ${ }^{135} \mathrm{Cs}$. These isotopes did not show such differences in the case of the GU1 sample, indicating that changes can be affected by numerous parameters. Differences between reflective boundaries and realistic surrounding can affect more strongly shortlived isotopes due to changes in neutron flux at the end of irradiation, but concentrations of such isotopes were not measured.

\subsection{GU3 and GU3' measurements}

As mentioned in the ARIANE report, the irradiated sample GU3 was analyzed in two different laboratories: in ITU (Germany): these measurements refer to the GU3 sample, and in SCK.MOL (Belgium), referring to the GU3' sample. The measurement periods are different for both samples, but are nevertheless similar (with cooling times of about 2 years for both samples). In the present study, results from both GU3 and GU3' are compared with the calculated compositions, simply taken into account their different cooling periods. The goal in the double measurement of the sample was for cross checking the nuclide inventory from both laboratories. As presented later and confirmed in the ARIANE report, it is generally believed that the results for GU3' (SCK.MOL) are more reliable than the ones for GU3 (ITU). Different comments in the ARIANE reports support such observations:

- for a number of isotopes $\left({ }^{147} \mathrm{Pm}, \mathrm{Ru}\right.$ isotopes), the GU3 results are rejected as results indicates spurious errors, overestimated absolute content, or underestimated uncertainties (the trend of ${ }^{147} \mathrm{Pm}$ and ${ }^{106} \mathrm{Ru}$ as a function of burnup for various ARIANE samples confirms this rejection),

- the GU3 sample indicates a ratio of the fractions in residue significantly lower than 1 , meaning that either ${ }^{101} \mathrm{Ru}$ is underpredicted, or that ${ }^{106} \mathrm{Ru}$ is overpredicted, 

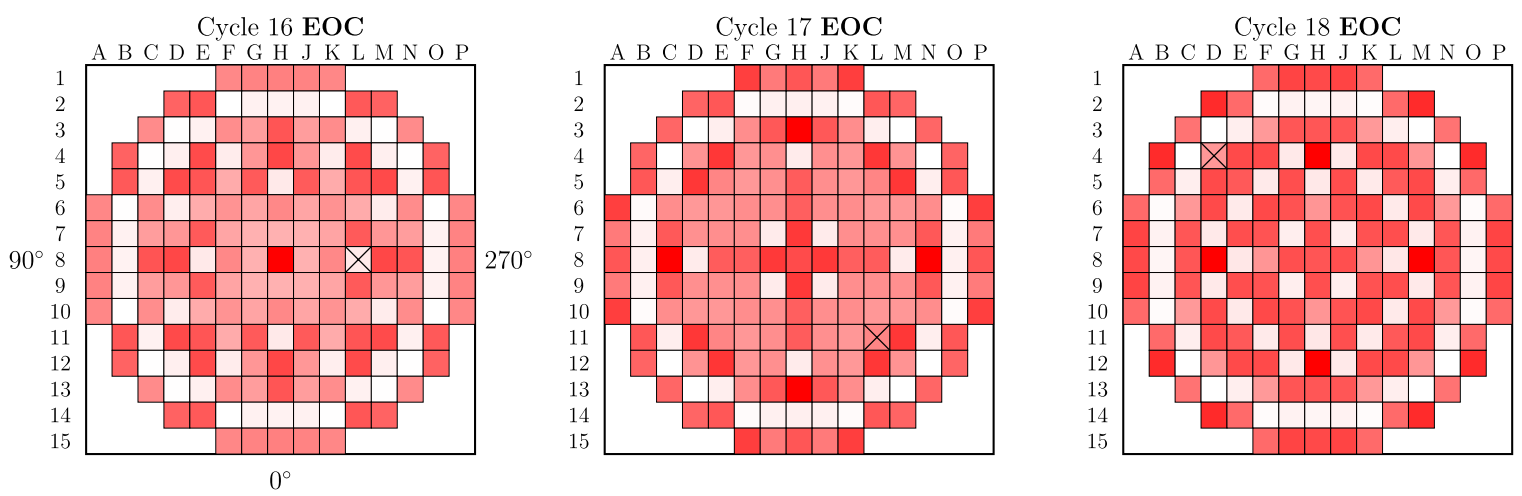

Fig. 2. Locations of the assemblies 16-01 (cycles 16 and 17) and 17-01 (cycle 18) containing the GU3 sample. The positions of both assemblies are indicated by a cross. The colors are proportional to the assembly burnup obtained from SIMULATE-3 at the end of each cycle (EOC).

- the deduced FIMA from the GU3 sample is 5 to $6 \%$ lower than the one from SCK.CEN, whereas the value from SCK.CEN agrees within $1.5 \%$ with the calculated value,

- in the case of ${ }^{133} \mathrm{Cs}$, its trend as a function of sample burnup indicates an overestimation for GU3 and an underestimation of its uncertainty.

As indicated, both results from GU3 and GU3' are compared to calculated values in the following, and simple average $\mathrm{C} / \mathrm{E}-1$ over all measured isotopes as well as the sample burnup show a better agreement with the GU3' values (see Tabs. A.1 and A.2 for the original reported measured values used in the present work).

Additionally, both laboratories report different values of ${ }^{148} \mathrm{Nd}$, with a difference of almost $5 \%$. In the following however, the same simulation input conditions will be used for both GU3 and GU3'; as demonstrated in next sections, this is implying that the calculated ${ }^{148} \mathrm{Nd}$ will agree well with the value of one laboratory (SCK.MOL), and less with the other one (ITU).

Finally, due to the differences between the reported isotopic concentrations, recommendations from the ARIANE report and from the Oak Ridge National Laboratory (ORNL) analysis can be found in references [5,8]. These values are also reported in Tables A.1 and A.2 for completeness and their interest from WPNCS subgroup 7 . In the case of the ORNL recommendations, as some values were proposed at the end of the irradiation time, the corresponding original concentrations from the ARIANE report are reported instead at the time of measurement. This facilitates the comparison between values, and avoid unnecessary calculations linked to the isotope decays.

\section{Simulation tools and calculation schemes}

General information on the simulations tools and inputs are presented in the following, first for the best-estimate calculations, then for calculated uncertainties. For uncertainties, three sources are considered: nuclear data, operating conditions and manufacturing tolerances. The reader is referred to the GU1 study for more details [6].

\subsection{Nominal simulations}

All quantities are obtained from the deterministic transport code CASMO5, and simulations of specific twodimensional assembly lattices. The same input descriptions are used for both GU3 and GU3' cases (except for the cooling times), as well as with different versions of CASMO5 and versions of libraries. As GU3 was irradiated in two different assemblies, their characteristics are modeled, such as the geometry, initial concentrations, irradiation histories, cooling periods and relocation characteristics (see Sect. 3.2 for details). The move of the concerned rod from one assembly to the other is automatically performed with a specific CASMO5 procedure.

For all calculations, the standard libraries for depletion chains are used (in CASMO5 nomenclature, the option "EXT" is not used). The default depletion solver is used for all calculations, namely the Chebyshev Rational Approximation (or CRAM). This is the default calculation scheme, compatible between the different CASMO5 library versions. In the case of CASMO5 version 2.13 with the e7r1.202.586.bin library, both calculations with and without the extended depletion chain were made. A comparison between isotopic concentrations indicated that most of them are not affected by the changes in the depletion chains (with relative differences between concentrations being smaller than 0.5\%). But the use of the extended depletion chain allows to obtain the concentration of ${ }^{151} \mathrm{Eu}$, which is not accounted for, if the normal depletion chain is used. Consequently, other $\mathrm{Eu}$ isotopes are more affected (by consecutive neutron capture), with relative changes up to $8 \%$ (for ${ }^{153} \mathrm{Eu}$ ).

A few different CASMO5 versions and nuclear data libraries are used in this validation effort, with a total of 12 different combinations, as presented in Table 1. As mentioned, the same input files (description of the sample irradiation) were used, developed with case number 1 from Table 1. The use of various libraries from European, American and Japanese evaluations can theoretically provide an unbiased representation of the current knowledge of nuclear data, possibly included in their covariance matrices. Details and analysis will be provided 
Table 1. Summary of the different CASMO5 calculation schemes performed in the present study for the twodimensional GU3 calculations.

\begin{tabular}{|c|c|c|c|c|}
\hline $\begin{array}{l}\text { CASMO5 } \\
\text { version }\end{array}$ & Library & $\begin{array}{l}\text { Processed } \\
\text { library version }\end{array}$ & $\begin{array}{l}\text { Covariance } \\
\text { library }\end{array}$ & $\begin{array}{l}\text { Case } \\
\text { number }\end{array}$ \\
\hline 2.03 .00 & ENDF/B-VII.1 & e7r1.201.586.bin & $\begin{array}{l}\text { ENDF/B-VIII.0, JEFF-3.3 } \\
\text { JENDL-4.0 }\end{array}$ & 1 \\
\hline 2.13 .00 & ENDF/B-VII.1 & e7r1.201.586.bin & & 2 \\
\hline 2.13 .00 & ENDF/B-VII.1 & e7r1.202.586.bin & & 3 \\
\hline 2.12 .00 & ENDF/B-VII.1 & e7r1.202.586.bin & & 4 \\
\hline $3.01 .00 \mathrm{~L}$ & ENDF/B-VII.1 & e7r1.202.586.bin & & 5 \\
\hline $3.01 .00 \mathrm{~L}$ & ENDF/B-VIII.0 & e8r0.300.586.bin & & 6 \\
\hline $3.01 .00 \mathrm{~L}$ & JEFF-3.1.1 & j311.200.586.bin & & 7 \\
\hline $3.01 .00 \mathrm{~L}$ & JEFF-3.2 & jeff32.t12.202.586.bin & & 8 \\
\hline 3.02 .00 & JEFF-3.2 & jeff32.t12.202.586.bin & & 9 \\
\hline 3.02 .00 & JENDL-4.0 & j4r0.200.586.bin & & 10 \\
\hline 3.02 .00 & ENDF/B-VII.1 & e7r1.201.586.bin & & 11 \\
\hline 3.02 .00 & ENDF/B-VIII.0 & e8r0.300.586.bin & & 12 \\
\hline
\end{tabular}

in the next sections. Note that in the case of the ENDF/B-VII.1 library, the processed library used by CASMO5 includes the ${ }^{239} \mathrm{Pu}$ evaluation from the JENDL4.0 library instead of the original one. Library names in Table 1 refer to the original CASMO5 names, indicating different releases of the processed libraries provided with the code (for instance release 201, or 202 for the ENDF/B-VII.1 library). To complement the estimation of uncertainties, and similar to the previous GU1 study, the effect of nuclear data, based on evaluated covariance files, on all isotopic contents are also calculated with the case number 1, as presented in Section 3.3.

\subsection{Cycle and relocation calculations}

For the present study, the assembly irradiations are simulated considering reflective boundaries, therefore assuming that the information for the neighboring assemblies is not known with enough details (as it can be found in the ARIANE report). First, the assembly 16-01 is irradiated during cycle 16 and 17 , taking into account the cooling time between these cycles and after cycle 17 . Independently, the assembly 17-01 irradiation is also simulated during cycle 17 . Then, using the procedure called "moverod" in CASMO5, the rod K13 from the assembly 16-01 is moved to position E14 in assembly 17-01 (see Fig. 1). Finally, the simulation of the assembly 17-01 with the relocated rod is performed for cycle 18 , followed by the subsequent cooling times until the measurement dates. For the calculation of the decay heat, the simulated cooling periods are simply extended up to a few hundred thousands of years. As an example of the calculated quantities, the $\mathrm{k}_{\infty}$ for the three cycles of interest is presented in Figure 3. In the present work, the irradiation description is not taken directly from the ARIANE report. Irradiation conditions for the CASMO5 input models are directly obtained from the core simulator SIMULATE-3 (using the BOHR method developed at PSI [9]): similar to the GU1 sample case, all cycle information for the

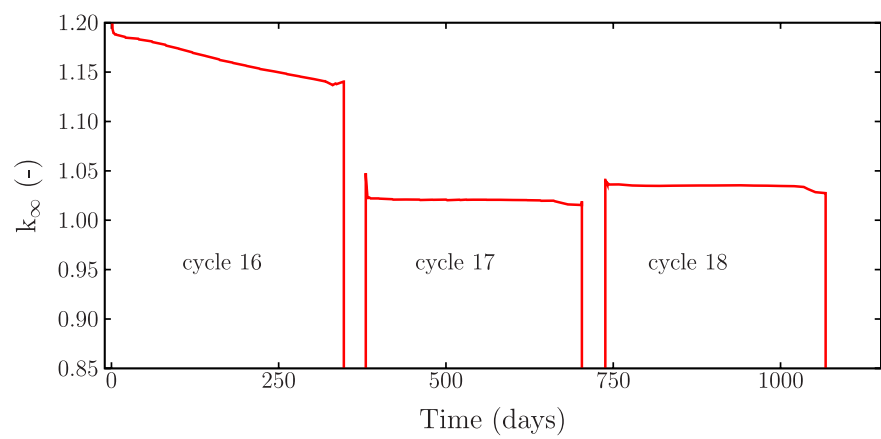

Fig. 3. Calculated $\mathrm{k}_{\infty}$ values during the three cycles of interest for the CASMO5 assembly model.

Gösgen reactor are available from the in-house database called CMSYS. Such database is usually used in the framework of safety analysis for core follow-up calculations (see details in Refs. [10-12]). Consequently, for each cycle, a large number of burnup steps are considered, and for each of them, the following parameters are changing: moderator and fuel temperatures, power density, reactor pressure, and eventually the control rod position. Typically, about 20 steps are considered for each cycle. Finally, to reach the recommended ${ }^{148} \mathrm{Nd}$ content (considered as a burnup indicator), the segment burnup can eventually be adjusted; in the present case, as the original calculated ${ }^{148} \mathrm{Nd}$ content was in good agreement with the reported value from the SCK.MOL (GU3') measurement, no adjustment was necessary.

Results for the sample nuclide inventory and the rod and assembly decay heat will be presented in the following sections.

\subsection{Uncertainty propagation}

In addition to the nominal cases with the different versions presented in Table 1, calculations are performed to estimate the uncertainties on the isotopic concentrations 
as well as on the decay heat. The CASMO5 version 2.03 will be used in these cases (case number 1), and the uncertainties on the input parameters and nuclear data are the same as for the study of the GU1 sample.

For all varied input quantities, the method of uncertainty propagation is simply based on Monte Carlo sampling with the repetition of the same calculation a large number of times (each time with a realization of the sampled input quantities). Each effect (except nuclear data being considered both all together as well as individually) is separately studied.

For nuclear data, the covariance information from the main three libraries are used in different calculations (ENDF/B-VIII.0 [13], JEFF-3.3 [14] and JENDL$4.0[15])$. It is worth noticing that the effects of thermal scattering and decay data are not included in this study. For fission yields, the approach presented in references [12, $16,17]$ is applied (sampling based on uncertainties from the evaluated libraries, plus a number of mass and charge normalizations).

For operating conditions, the following four quantities are separately and independently varied: fuel and moderator temperature (TFU and TMO, considering a uniform distribution with a standard deviation of $2 \%$ ), the boron concentration (or BOR, also considering a uniform distribution with a standard deviation of $2 \%$ ), and finally the burnup value of each depletion step (DEP, with a uniform distribution and a standard deviation of $0.25 \%)$. The variations are applied at the beginning of the simulations and all values are changed accordingly (for instance, all TMO are increased by $0.1 \%$ during a cycle depletion).

For manufacturing tolerances, four quantities were considered: radii of the fuel rods and guide tubes (RAD, for 32 pins surrounding and including the GU3 sample), the fuel pin and guide tube position shifts in the $\mathrm{X}$ and $\mathrm{Y}$ positions (X-Y), the fuel density and ${ }^{235} \mathrm{U}$ enrichment (DEN+ENR) and the pin pitch (called PITCH). These four quantities are varied given uniform distributions with a standard deviation of $0.5 \%$. All these standard deviations (except for nuclear data) are based on expert knowledge, and were also used in the study of the GU1 sample.

Contrary to the GU1 sample, two assemblies are used during the GU3 irradiation. For the nuclear data, the same perturbation factors are used for both assemblies. For other quantities, for instance the fuel density, they are randomly modified at the first assembly irradiation, one assembly independently of the other.

\section{Sample burnup and burnup indicators}

As presented in the ARIANE report, the GU3 sample burnup was estimated to be $52.5 \mathrm{MWd} / \mathrm{kgU}$. Compared to literature data, references $[8,18]$ analyzed the GU3 sample (among others) with the SCALE5 package and adopted the ARIANE recommended value of $52.5 \mathrm{MWd} / \mathrm{kgU}$. In the present work, a few values are obtained from the CASMO5 calculations due to the changes of libraries and code versions (the change in transport solutions have a larger impact than the nuclear data, given the small variations of burnup values). As both GU3 and GU3' are simulated with the same input descriptions (except cooling times after irradiation), the same value for the sample burnup is obtained. They will, nevertheless, correspond to different agreement with the reported ${ }^{148} \mathrm{Nd}$ contents from both laboratories. It is worth noticing that the current simulation models are relatively independent of the reported experimental values: no adjustment was performed, and the irradiation conditions were obtained from a different source than the ARIANE report.

Taking into account the 12 cases from Table 1, the average sample burnup corresponds to $52.1 \mathrm{MWd} / \mathrm{kgU}$ with a standard deviation smaller than $0.1 \mathrm{MWd} / \mathrm{kgU}$ : it does not significantly change using different CASMO5 or libraries versions.

The use of the ${ }^{148} \mathrm{Nd}$ concentration as a burnup indicator is a general practice and is recommended as a standard method [19]. The average calculated value is $0.621 \mathrm{mg} / \mathrm{gU}$ (for both GU3 and GU3'), which can be compared to the measured values of 0.596 for GU3, 0.626 for GU3', and $0.587 \mathrm{mg} / \mathrm{gU}$ for the recommendation of reference [8]. Based on the ${ }^{148} \mathrm{Nd}$ concentration from ITU, the calculated sample burnup is $49.7 \mathrm{MWd} / \mathrm{kgU}$, lower by almost $5 \%$ compared to the SCK.MOL and ARIANE values. Consequently, this indicates that the present simulations agrees better with the GU3' (from SCK.MOL) reported ${ }^{148} \mathrm{Nd}$ content as well as with the burnup value given in the ARIANE report.

Other $\mathrm{Nd}$ isotopes can be used as indicators of the sample burnup. Considering ${ }^{143-146,150} \mathrm{Nd}$ isotopes can confirm the measured value of ${ }^{148} \mathrm{Nd}[20]$. As presented in the next section (see as well Tab. B.1), the agreement between calculated and measured concentrations for these $\mathrm{Nd}$ isotopes is better in the case of the GU3' sample, therefore confirming the GU3 ${ }^{148} \mathrm{Nd}$ content.

Finally, ${ }^{137} \mathrm{Cs}$ is also considered as a reliable burnup indicator, for reasons similar to ${ }^{148} \mathrm{Nd}$ : low capture cross section, and yields from ${ }^{235} \mathrm{U}$ and ${ }^{239} \mathrm{Pu}$ being approximately the same (leading to a linear relationship between ${ }^{137} \mathrm{Cs}$ content and burnup [21]). The calculated concentration for ${ }^{137} \mathrm{Cs}$ also agrees well with the reported value from GU3', within almost one experimental standard deviation.

Regarding the experimental uncertainty for the GU3' ${ }^{148} \mathrm{Nd}$ concentration, a value of almost $0.3 \%$ is reported, sensibly smaller than the GU3 value $(\simeq 1.2 \%)$. Such small uncertainty leads to a burnup uncertainty of 0.1 $\mathrm{MWd} / \mathrm{kgU}$, similar to the spread of CASMO5 calculations corresponding to Table 1. As presented in Section 6.2 and Table B.6, the calculated uncertainty on ${ }^{148} \mathrm{Nd}$ concentration is closer to $1 \%$, corresponding to $0.5 \mathrm{MWd} / \mathrm{kgU}$.

As a conclusion, a number of comparisons between calculated and measured isotope concentrations (considered as burnup indicators) tends to indicate that the deduced burnup value from the GU3' measurements (SCK.MOL) is closer to the simulated conditions. For the rest of the analysis, concentrations from both laboratories will be compared with the present calculations, but the recommended sample burnup is $52.5 \pm 0.5 \mathrm{MWd} / \mathrm{kgU}$. 

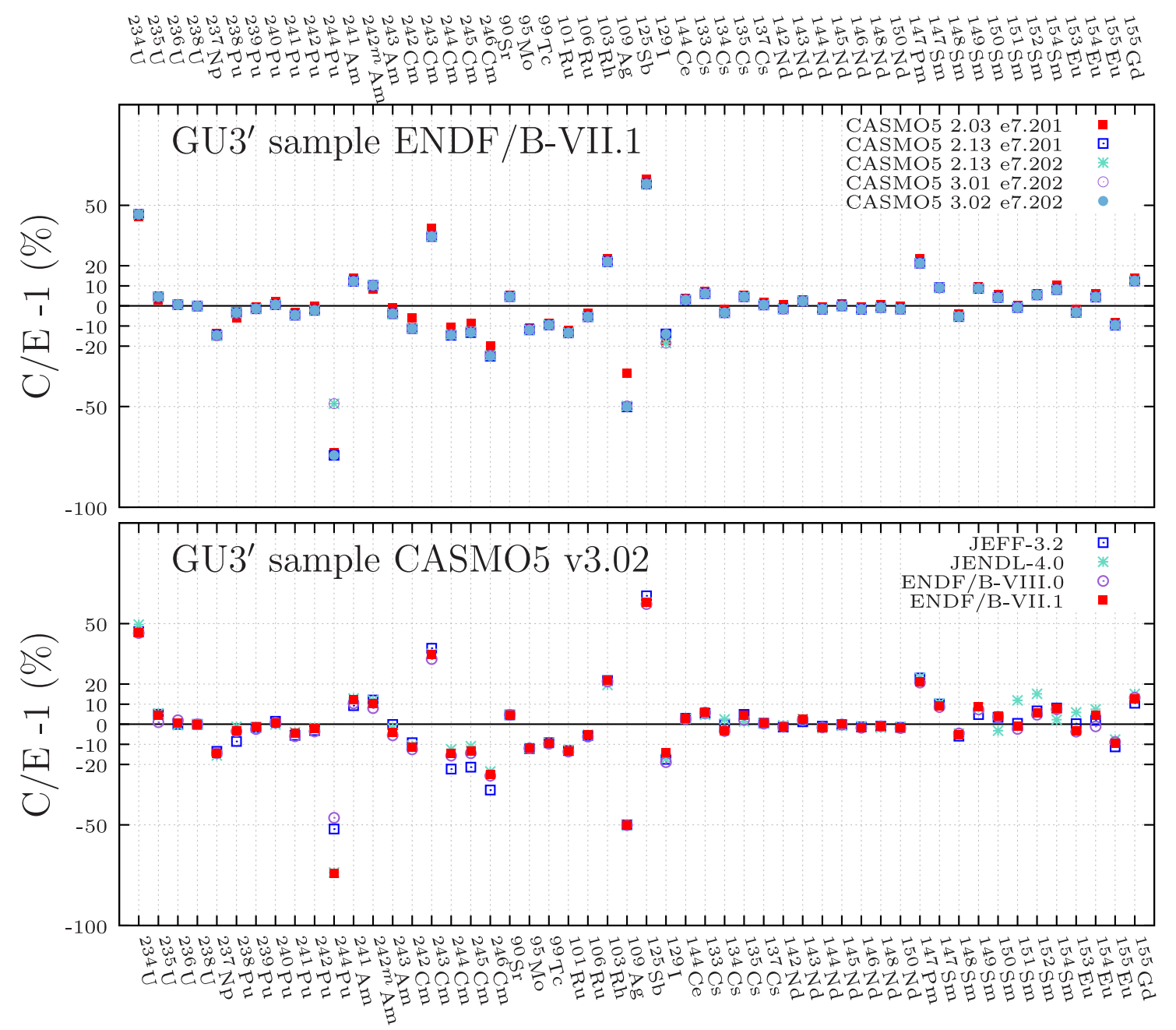

Fig. 4. Comparisons between calculated and measured values from SCK.CEN (C/E-1) for each measured isotopes from different calculations for the GU3' sample; top: various CASMO5 versions with the ENDF/B-VII.1 library, bottom: same CASMO5 version for four different libraries.

\section{Post irradiation examination results}

In the following, the calculated isotopic compositions with the different CASMO5 versions are compared to the values of GU3 and GU3'. As this represents a large amount of numbers, only values from case 1 of Table 1 are reported in details, the other ones being only presented in terms of average $\mathrm{C} / \mathrm{E}$ values. For case 1 (CASMO5 version 2.03 with the ENDF/B-VII.1 library), results are presented in terms of $\mathrm{C} / \mathrm{E}-1$ (in\%) for each isotopes (see Fig. 4 and Tabs. 2 and B.1).

First the nominal $\mathrm{C} / \mathrm{E}$ ratios are compared (without calculated uncertainties), then the effects of the variations nuclear data, operating conditions and manufacturing tolerances are assessed, with their individual contributions.

\subsection{Nominal calculations}

The C/E-1 values for each measured isotopic concentrations are presented in Figure 4 in the case of the GU3'
(SCK.CEN) sample. Numerical values for both GU3 and GU3' are given in Table B.1. For ${ }^{99} \mathrm{Tc},{ }^{95} \mathrm{Mo},{ }^{125} \mathrm{Sb}$, ${ }^{101,106} \mathrm{Ru},{ }^{103} \mathrm{Rh}$ and ${ }^{109} \mathrm{Ag}$, the sum of dissolved and residue quantities are added. Generally, the amounts of isotopes left in the residue of the GU3 sample are higher than for GU3'. The values for different CASMO5 code versions are plotted, but only the ones for CASMO5 version 2.03 with the library release 201 are given in the tables. As observed, all CASMO5 values are similar, except for ${ }^{244} \mathrm{Pu}$ and ${ }^{109} \mathrm{Ag}$. This was already observed for the GU1 sample [6] for ${ }^{244} \mathrm{Pu}$, and was interpreted as the introduction in the standard depletion chain (for the latest library release 202) of the ${ }^{244 m} \mathrm{Am}$ production and decay. As ${ }^{244 m} \mathrm{Am}$ decays to ${ }^{244} \mathrm{Pu}$, it contributes to increase the amount of ${ }^{244} \mathrm{Pu}$, therefore improving the $\mathrm{C} / \mathrm{E}$ value. One should notice anyway that the concentration of ${ }^{244} \mathrm{Pu}$ is relatively small, being $10^{4}$ times less than ${ }^{239} \mathrm{Pu}$. In the case of ${ }^{109} \mathrm{Ag}$, such effect was not noticed for the GU1 sample, as the $\mathrm{C} / \mathrm{E}-1$ was larger than $+500 \%$. It is due to the CASMO5 change in the fission yield of ${ }^{241} \mathrm{Pu}$ for ${ }^{109} \mathrm{Pd}$ (which decays to ${ }^{109} \mathrm{Ag}$ ). 
Table 2. Comparison of average C/E-1 (in\%) between different types of calculations for GU3 and GU3', see text for details.

\begin{tabular}{|c|c|c|c|c|c|c|}
\hline \multirow[t]{2}{*}{ Code } & \multirow[t]{2}{*}{ Library } & \multirow[t]{2}{*}{ case } & \multicolumn{2}{|c|}{ GU3' (SCK) } & \multirow{2}{*}{$\begin{array}{l}\text { GU3 (ITU) } \\
45 \text { isotopes } \\
\text { AC/FP }\end{array}$} & \multirow{2}{*}{$\begin{array}{l}\text { Reference [8] } \\
50 \text { isotopes } \\
\mathrm{AC} / \mathrm{FP}\end{array}$} \\
\hline & & & 52 isotopes & 45 isotopes & & \\
\hline CASMO5 2.03 & ENDF/B-VII.1 & 1 & $-2 /+3$ & $+1 /+2$ & $-1 /+1$ & $+2 /+1$ \\
\hline CASMO5 2.13 & ENDF/B-VII.1 & 2 & $-3 /+1$ & $+0 /+1$ & $-2 /+0$ & $+1 /-0$ \\
\hline CASMO5 2.12, 2.13 & ENDF/B-VII.1 & 3,4 & $-2 /+1$ & $+0 /+1$ & $-2 /+0$ & $+1 /+3$ \\
\hline CASMO5 3.01, 3.02 & ENDF/B-VII.1 & 5,11 & $-3 /+1$ & $+0 /+1$ & $-2 /+0$ & $+1 /+3$ \\
\hline CASMO5 3.01, 3.02 & ENDF/B-VIII.0 & 6,12 & $-3 /+1$ & $-0 /+0$ & $-3 /+0$ & \\
\hline CASMO5 3.01 & JEFF-3.1.1 & 7 & $-10 /+5$ & $-4 /+2$ & $-6 /+1$ & $-2 /+6$ \\
\hline CASMO5 3.01, 3.02 & JEFF-3.2 & 8,9 & $-3 /+1$ & $-1 /+1$ & $-4 /+0$ & $-0 /+3$ \\
\hline CASMO5 3.02 & JENDL-4.0 & 10 & $-2 /+2$ & $+1 /+2$ & $-2 /+1$ & $+2 /+4$ \\
\hline SCALE [18] & SCALE-6 & & $-1 /+2$ & & & \\
\hline WIMS [22] & JEFF-3.1 & & $-1 /+8$ & & $-4 /-1$ & \\
\hline VESTA [23] & ENDF/B-VII.0 & & $-1 /-2$ & & $-5 /+13$ & \\
\hline VESTA [23] & ENDF/B-VII.1 & & $+0 /-4$ & & $-5 /+11$ & \\
\hline VESTA [23] & ENDF/B-VIII.0 & & $+0 /-2$ & & $-5 /+14$ & \\
\hline VESTA [23] & JEFF-3.1 & & $-2 /+0$ & & $-6 /+13$ & \\
\hline VESTA [23] & JEFF-3.2 & & $+0 /+0$ & & $-6 /+14$ & \\
\hline VESTA [23] & JEFF-3.3 & & $+1 /-1$ & & $-5 /+14$ & \\
\hline TRITON [8] & SCALE-5.1 & & & & & $+1 /+6$ \\
\hline
\end{tabular}

As a last general comment for the calculations, the agreement for the metallic fission products, which are difficult to dissolve, is not as good as for the other fission products or for the actinides. This is also not specific to the GU3 sample and is common to many (if not all) PIE samples.

A global comparison for average $\mathrm{C} / \mathrm{E}$ values is presented in Table 2 between the present results and a selection from the literature. Numbers presented in this table are simple average of $\mathrm{C} / \mathrm{E}-1$ ratios based on the individual values given in these references. In the case of the GU3' sample, two averages are presented: one with all measured isotopes (in total, 52 isotopes), and one with 45 isotopes for a direct comparison with GU3 (for GU3, 45 isotopes were measured and not 52). Not presented in this table are the spread of the individual C/E-1 ratios: such spread can be quantified by standard deviations, varying from 15 to $40 \%$.

The first remark concerns results from similar processed libraries and CASMO5 versions: all average values are relatively close, given the mentioned changes $\left({ }^{244} \mathrm{Pu}\right.$ and ${ }^{109} \mathrm{Ag}$ ). Compared to other studies, various levels of agreements can be obtained depending on the isotope of interest. For the present work, the average $\mathrm{C} / \mathrm{E}-1$ values indicate a slight tendency for a better agreement with the experimental values from the GU3' sample. Recommended values from reference [8] and ARIANE values lead to results alike. In the case of the GU3 sample and the CASMO5 calculations, the largest differences are obtained for ${ }^{244,245} \mathrm{Cm}$ and a number of metallic fission products (among which ${ }^{95} \mathrm{Mo},{ }^{101,106} \mathrm{Ru},{ }^{103} \mathrm{Rh}$ ), see tabulated values in Table B.1.

It is interesting to note that in the present calculations, the agreement with ${ }^{148} \mathrm{Nd}$ is better for the GU3' sample.
Still, in the case of GU3, values from Table 2 indicate an agreement almost as good as for GU3'. This is due to compensation from individual isotopes: for actinides, values for ${ }^{243} \mathrm{Am}$ and ${ }^{244,245} \mathrm{Cm}$ strongly differ between GU3 and GU3', but average C/E-1 are finally close. This indicates that average numbers as presented in such table are of limited help for a detailed understanding. Following individual comparisons of ratios as presented in Table B.1, a better agreement seems to be obtained with the reported values from GU3' (SCK.CEN sample). The recommendation from reference [8] also leads to good agreement, following from a choice of measured values between GU3 and GU3'.

As a final test calculation in favor of the measurements from GU3', the calculation presented in case 1 can be repeated, but with a lower target sample burnup in order to match the GU3 ${ }^{148} \mathrm{Nd}$ content. In such calculation, the sample burnup is $49.7 \mathrm{MWd} / \mathrm{kgU}$ and the average C/E-1 values for the GU3 sample are $-5 /-3$ for the actinides and fission products, respectively. These average values are not as good as the ones from Table B.1, being -1 and +1 .

The comparison with simulations presented in other references should be done with care. As mentioned, the same conditions for the simulation of GU3 and GU3' were applied in this work, hence leading for instance to different levels of agreement with ${ }^{148} \mathrm{Nd}$. In references [22] and [23], different simulation conditions or renormalization factors were applied for GU3 and GU3'. In the case of reference [22] for instance, the agreement with both GU3 and GU3 ${ }^{148} \mathrm{Nd}$ values leads to $\mathrm{C} / \mathrm{E}$ ratios of 1.0 .

The VESTA results as presented in reference [23], show better agreement for GU3' than for GU3. It is especially 
true for fission products, which come from a large overestimation for ${ }^{99} \mathrm{Tc},{ }^{95} \mathrm{Mo}$ and ${ }^{101} \mathrm{Ru}$, explaining an overestimation of +10 to $15 \%$. As noted in reference [23], the ITU values are suspected to exhibit measurement issues as the estimated VESTA burnup of the ITU sample, based on combined values of the Nd isotopes (sum of the ${ }^{145} \mathrm{Nd},{ }^{146} \mathrm{Nd}$ and ${ }^{148} \mathrm{Nd}$ ), is of the order of 6 to $7 \%$ below the reported ARIANE burnup value.

In the following, the uncertainties due to various input parameters for each isotopic concentration are presented. Calculations are performed for the GU3' sample and similar results are expected for GU3, as only the cooling periods are (modestly) varying between the two simulations. The calculation case is number (1) from Table 1. Because the same approach was followed for the GU1 sample [6], present uncertainties are also compared to this sample.

\subsection{Uncertainties due to nuclear data}

The effect of the evaluated nuclear data covariances (cross sections, nubar, fission spectra and fission yields) is assessed by repeating many times the same calculation, each time with a different realization of random values. This method was already applied for various samples, SNF and full core calculations, based on a modified version of CASMO5 with the tool SHARK-X. This tool allows to randomly vary nuclear data such as cross sections, based on covariance matrices; details are provided for instance in references [6,24-26] (interested readers can also find details on other applications of stochastic methods for spent fuel in Refs. [27-30]). As for the previous studies, the variations of nuclear data are performed in 19 energy groups, being adequate for PWR calculations, and relative perturbation factors are applied for each group. The nominal library is ENDF/B-VII.1 and perturbation factors are obtained for the three libraries ENDF/B-VIII.0, JEFF-3.3 and JENDL-4.0 [13-15]. Global results for each measured isotopes of the GU3' sample at the time of measurements are presented in Tables B.2 and B.3, together with a comparison for the GU1 sample.

One can first notice that there are relatively important differences when using the three covariance files from the above libraries, both for GU1 and GU3. This is not the case for the main actinides, but ${ }^{238,240,242} \mathrm{Pu}$ as well as ${ }^{243} \mathrm{Cm}$ have uncertainties varying up to a factor 2 . Fission products can present stronger differences, especially for isotopes highly sensitive to fission yield uncertainties $\left({ }^{109} \mathrm{Ag},{ }^{125} \mathrm{Sb},{ }^{133-135} \mathrm{Cs},{ }^{154} \mathrm{Sm}\right)$. For ${ }^{155} \mathrm{Eu}$ and ${ }^{155} \mathrm{Gd}$, there are no covariance information for the natural elements Eu and Gd in JENDL-4.0, which lower the calculated uncertainties on their concentrations.

In addition to the uncertainties due to the covariance files in libraries, Tables B.2 and B.3 also contain other variations in the $5^{\text {th }}$ and $6^{\text {th }}$ columns. They both represent the spread of the calculated data, either in terms of a standard deviation, or in terms of differences between extreme $\mathrm{C} / \mathrm{E}-1$ values. It is another quantification of the spread of data; if the nuclear data covariances correctly represent the unknown knowledge, and if nuclear data libraries are independent, then the separation between extreme ratios is not expected to be too far from the uncertainties due to nuclear data (the term "too far" being roughly equivalent to "less than a factor 3"). For instance, in the case of ${ }^{148} \mathrm{Nd}$, the uncertainties due to nuclear data are between 0.4 and $0.6 \%$, whereas the extreme values are $2.2 \%$ apart; this indicates that the spread of $\mathrm{C}$ from the nuclear data covariances and the extreme values are "weakly" consistent (three times the calculated uncertainty, or $3 \sigma$ is lower than $2.2 \%$ ). In the case of ${ }^{137} \mathrm{Cs}$, the extreme values are separated by $1.6 \%$, and the calculated uncertainties are larger than twice this value. It indicates that the knowledge represented by the nominal values is more alike among libraries than their associated uncertainties. Finally, the last case corresponds to spreads of extreme values similar to the calculated uncertainties, such as for ${ }^{239} \mathrm{Pu}$. The most striking differences are observed for ${ }^{244} \mathrm{Pu}, \mathrm{Cm}$ isotopes, ${ }^{106} \mathrm{Ru},{ }^{150,152} \mathrm{Sm},{ }^{153,154} \mathrm{Eu}$.

Such uncertainties are essential components to the total calculated uncertainties for each isotopes. As it is presented in the next sections, nuclear data uncertainties are often (or even systematically) the main contributors to the total isotopic uncertainties, and consequently to the decay heat uncertainties.

\subsection{Partial effects of nuclear data}

Partial effects of nuclear data can be calculated by simply varying either the fission yields (called FY), or the rest (cross sections, nubar and fission spectra, called XS), and by repeating the CASMO5 calculations with the selected set of random inputs. For both categories, 200 random samples were used, providing an error on the standard deviation of about $7 \%$. By doing so, the cross effects of simultaneously varying these quantities are not captured, and the sum of the effects might not be equal to the values presented in Table B.2. These separated effects of FY and XS are presented in Figure 5, as relative contributions to the total uncertainties (varying together FY and XS). As mentioned, their root-sum-of-squares (RSS) might be greater than $100 \%$ ( $100 \%$ being equal to the total uncertainty when simultaneously varying FY and XS) due to cross correlations (and covariances), and to the fact that a limited number of samples was realized. A similar study was done for the GU1 sample and results are alike. Naturally, actinides are mainly affected by XS, whereas fission products can be sensitive to both XS and FY. Globally the same ratios were observed for the GU1 sample, indicating that the differences in these samples (burnup, initial enrichment, cooling time and relocation) do not play a major role in the XS and FY contributions.

The effect of the sample burnup can still change the ${ }^{235} \mathrm{U}$ and ${ }^{239} \mathrm{Pu}$ contributions to the integrated fission events. In reference [6], it was noticed that the main contributors to the fission rates are ${ }^{235} \mathrm{U},{ }^{239} \mathrm{Pu},{ }^{241} \mathrm{Pu}$ and ${ }^{238} \mathrm{U}$, with $44,38,10$ and $8 \%$ of the total integrated fission events, respectively. In the case of GU3, as the sample burnup is lower (about 52 compared to $59 \mathrm{MWd} / \mathrm{kgU}$ ), the contributions are changed to $50,35,7$ and $8 \%$ for these four actinides, respectively. This change between 


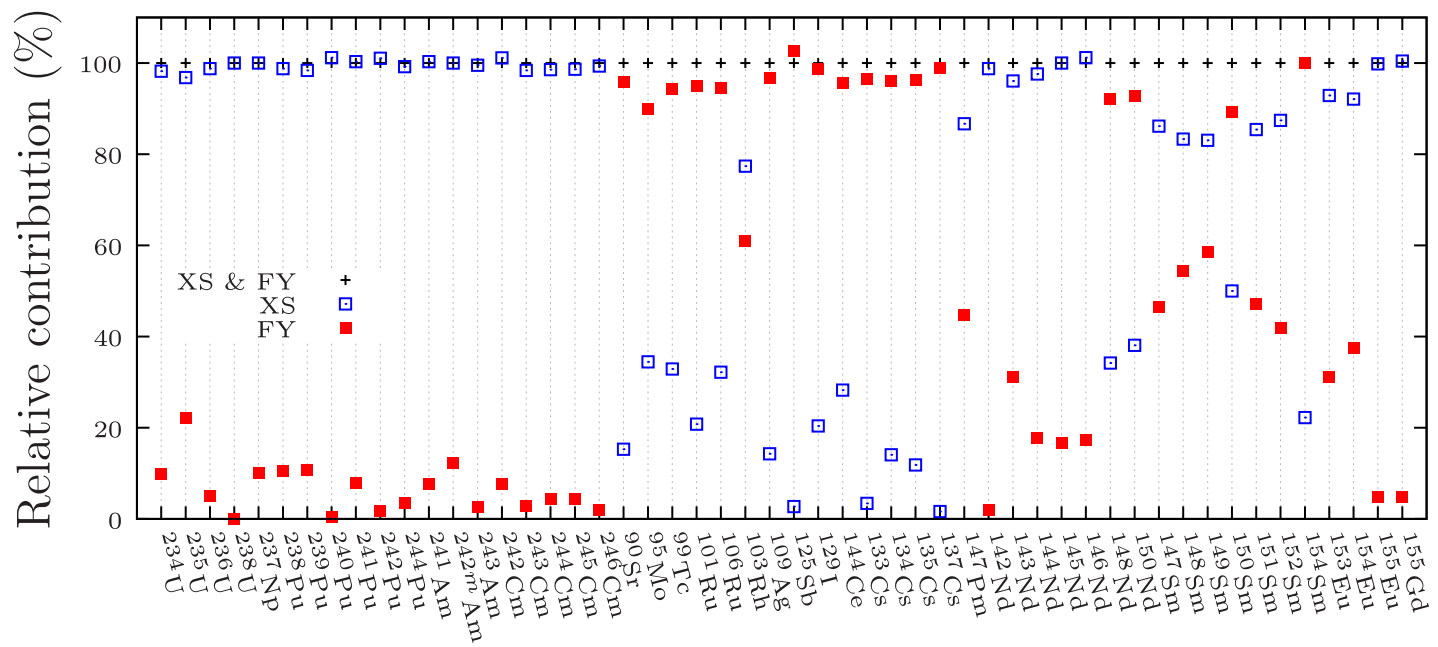

Fig. 5. Relative contributions of the cross sections (called XS) and fission yields (called FY) to the total uncertainties based on the ENDF/B-VIII.0 covariance library.
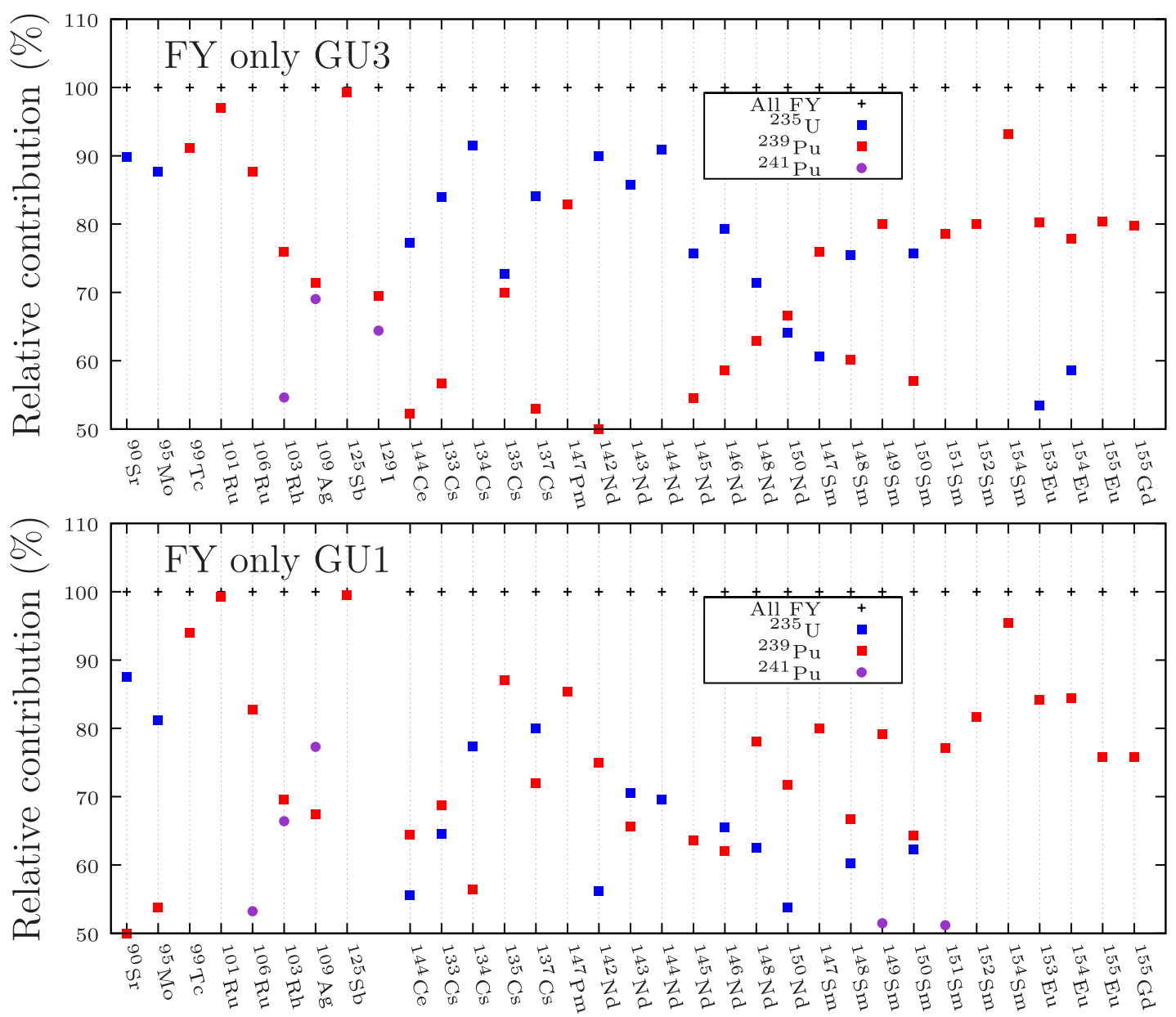

Fig. 6. Top: relative contributions of fission yields (called FY) to the total FY uncertainties for fission products of the GU3 sample. Bottom: same for the GU1 sample [6].

${ }^{235} \mathrm{U}$ and ${ }^{239} \mathrm{Pu}$ is indeed reflected in Figure 6, showing for the FY the main individual contributors to the uncertainties for each measured fission product. Actinides are not represented as they are scarcely affected by FY. It can be observed that the difference between GU1 and GU3 is a lower ${ }^{235} \mathrm{U}$ contribution for GU1. As the FY uncertainties 

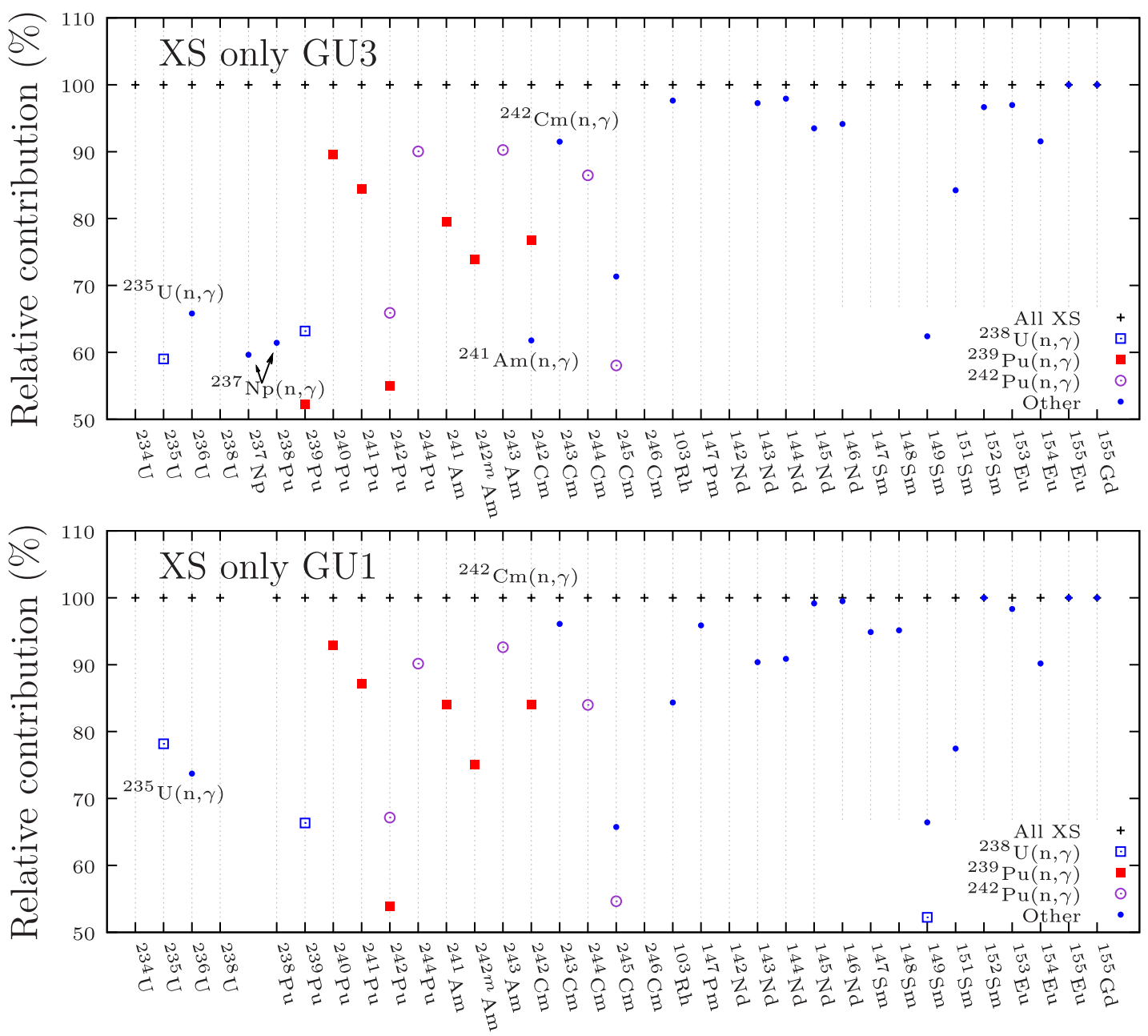

Fig. 7. Top: relative contributions of cross sections, nubar and fission spectra (called XS) to the total XS uncertainties for fission products and the GU3 sample. Bottom: same for the GU1 sample [6].

are different for these two actinides, the fission product uncertainties will therefore be different between GU1 and GU3.

In the case of the various XS contributions, the variations are presented in Figure 7 for actinides and fission products affected by the XS covariances (the other isotopes, mainly depending on FY covariances, are not presented). As it was noticed in reference [6], capture cross sections are the main contributors to the uncertainties on these isotope concentrations; in the case of actinides, the uncertainties due to the fission cross sections (as well as nubar and fission spectra) are of second order. For fission products, many capture cross sections can affect a specific isotope concentration: the ones participating to the production of an isotope (for instance for ${ }^{133} \mathrm{Cs},{ }^{143,145} \mathrm{Nd}$ ), in addition to the ones for their disappearance (as in the case of $\left.{ }^{103} \mathrm{Rh},{ }^{151,152} \mathrm{Sm},{ }^{153} \mathrm{Eu}\right)$.

Additionally, three capture cross sections for actinides affect actinide concentrations: ${ }^{238} \mathrm{U}(\mathrm{n}, \gamma),{ }^{239} \mathrm{Pu}(\mathrm{n}, \gamma)$ and for heavier actinides, ${ }^{242} \mathrm{Pu}(\mathrm{n}, \gamma)$. This can be observed for both samples. Marginally, other capture cross sections can change specific isotopes, such as ${ }^{235} \mathrm{U}(\mathrm{n}, \gamma){ }^{236} \mathrm{U},{ }^{237} \mathrm{~Np}(\mathrm{n}, \gamma){ }^{238} \mathrm{~Np}$ (decaying to $\left.{ }^{238} \mathrm{Pu}\right)$, and
${ }^{241} \mathrm{Am}(\mathrm{n}, \gamma){ }^{242} \mathrm{Am}$ (partially decaying to ${ }^{242} \mathrm{Cm}$ ). Similar trends are observed for GU1 and GU3.

\subsection{Uncertainties from operating conditions and manufacturing tolerances}

Apart from the uncertainties due to nuclear data, other effects due to unknowns of operating conditions can modify the nuclide inventory. Details of the varied parameters and their standard deviations are given in Section 3.3. Calculated uncertainties for each isotope are presented in Tables B.4 and B.5. The first remark is that generally, the uncertainties due to nuclear data are the dominant ones. For actinides, the moderator density ( related to the moderator temperature) is also an important source of uncertainties, followed by the pin pitch. For fission products, nuclear data are again the first source of uncertainties. The RSS comparison between GU1 and GU3 (and GU3') does not indicate significant differences, pointing out that the differences between both samples (initial enrichment, sample burnup, cooling time and relocation effect) are not impacting the calculated 
uncertainties (notwithstanding the mass balance effect of $2 \%$ for GU1 which is not reported in these tables).

Such RSS uncertainties are compared in the following with biases from the measurement, and are also consistently propagated to decay heat calculations.

\subsection{Other uncertainty sources}

A number of sources of uncertainties is not considered in this study: decay data (half lives, energy release, decay types, branching ratios), as well as bowing effects, impact of simulated irradiation steps (how concentrations are changing when using less detailed irradiation history) and calculation methods. Therefore the present study is not exhaustive in terms of uncertainty sources.

\section{Summary of PIE C/E and uncertainties}

The complete list of isotopic uncertainties are presented in Tables B.2-B.5. As for the GU1 sample, a range of uncertainties for nuclear data is provided, given that different library covariances lead to different isotopic uncertainties. A summary of uncertainties (both calculated and experimental), as well as biases are presented in Table B.6. A number of remarks is proposed in the following.

\subsection{Comparison of uncertainties}

All the calculated uncertainties are combined using the RSS for each isotopes, under the name $\Delta \mathrm{C}_{\max }$ in Table B.6. For this, only the maximum uncertainties for nuclear data is used. This quantity neglects the cross effects of simultaneously varying all the quantities. Among them, as noticed before, the nuclear data uncertainties are the largest components. The reported experimental uncertainties correspond to the GU3' (SCK.CEN) sample, being in general larger than for GU3. They strongly vary between isotopes, and combining them with $\Delta \mathrm{C}_{\max }$ (with the RSS) can lead to quantities larger than the bias. In such cases, uncertainties can be used to explain the origin of the biases (e.g. for ${ }^{235,236} \mathrm{U}$ and ${ }^{238-242} \mathrm{Pu}$ ). In other cases, differences between biases and calculated uncertainties are still large (see ${ }^{234} \mathrm{U},{ }^{244} \mathrm{Pu}$ and a number of fission products). In the following, as for the GU1 sample, the bias values $\mathrm{C} / \mathrm{E}-1$ can be taken into account to provide a unique uncertainty per isotope, called in the next section the "expanded uncertainty".

\subsection{Expanded uncertainties}

Results in Tables B.2-B.6 provide experimental and calculated uncertainties $(\Delta \mathrm{E}$ and $\Delta \mathrm{C})$ as well as biases $(\delta=C / E-1)$ as three independent quantities. This is useful for the understanding of the effects of each contribution; it can also help to calculate global uncertainties, combining these three sources of information, as expressed in the guidelines of the National Institute of Standards and Technology [31] and in Guide to the Expression of Uncertainty in Measurement [32]. Details can be found in these two references and in reference [6]; considering one standard deviation of a Normal distribution, two expanded uncertainties $\Delta_{\text {expanded }}$ can be calculated, called $\operatorname{RSS} U$ (being the RSS of $\Delta \mathrm{E}, \Delta \mathrm{C}$ and $\delta$ ) and $\mathrm{SUM} U$ (being an asymmetric range of uncertainty).

They are presented in Table B.6, together with different quantities. Only the maximum values due to nuclear data are used, but such calculations can also be done with the minimum values. As observed, the values $\Delta_{\text {expanded }}$ can strongly differ from $\Delta \mathrm{C}$ if the bias (or $\Delta \mathrm{E}$ ) is large. They also differ between GU1 and GU3, as biases $\delta$ and $\Delta \mathrm{E}$ are different for these samples.

Such expanded uncertainties can prove useful in the assessment of prediction power if they are obtained for a number of samples, but are of limited use when considered individually, as they reflect the characteristics of a particular case. It is nevertheless a convenient way to combine information, as uncertainties alone cannot be statistically significant when biases exist.

In the following, the assembly decay heat will be calculated, together with expanded uncertainties, taking into account the isotope biases and uncertainties.

\section{Decay heat and decay heat uncertainties}

Similar to the assembly containing the GU1 assembly, the decay heats of the assembly and rod hosting the GU3 sample can be calculated based on the previous CASMO5 models. Three cases will be considered: the actual assembly 17-01 with the relocated rod, the assembly 17-01 without the relocated rod, and finally only the rod containing the GU3 sample (which has a higher burnup than the rest of the assembly 17-01). Details are provided in the following and in Tables B.7 and B.8.

\subsection{Calculated decay heats and uncertainties}

The CASMO5 models for the three proposed cases can be used to calculate decay heats up to a million year, using the SNF-lite module of CASMO5. Values from 100000 to a million years are for indication only, as SNF-lite is not recommended up to 100000 years. With the same variations of nuclear data and parameters, the nominal calculations and the uncertainties on decay heats are consistent with the calculations of the GU3 isotopic compositions. Regarding the nominal values, the three decay heats are presented in Figure 8 (top). As observed, the three cases (assembly 17-01 with and without relocation, and the GU3 rod) present different, but close decay heats (relatively to their mass). The original assembly (without rod relocation) and the one with relocation do not present a strong difference, as only one fuel rod out of 205 was replaced (maximum difference of about $20 \%$ at the end of irradiation). For the GU3 rod, a higher decay heat can be observed (due to the higher rod burnup compared to the assembly), and the maximum difference can reach a factor 2 .

Regarding the calculated uncertainties, some differences can be observed (Fig. 8 middle for nuclear data), but the impact of the three cases is minimal (values are provided 


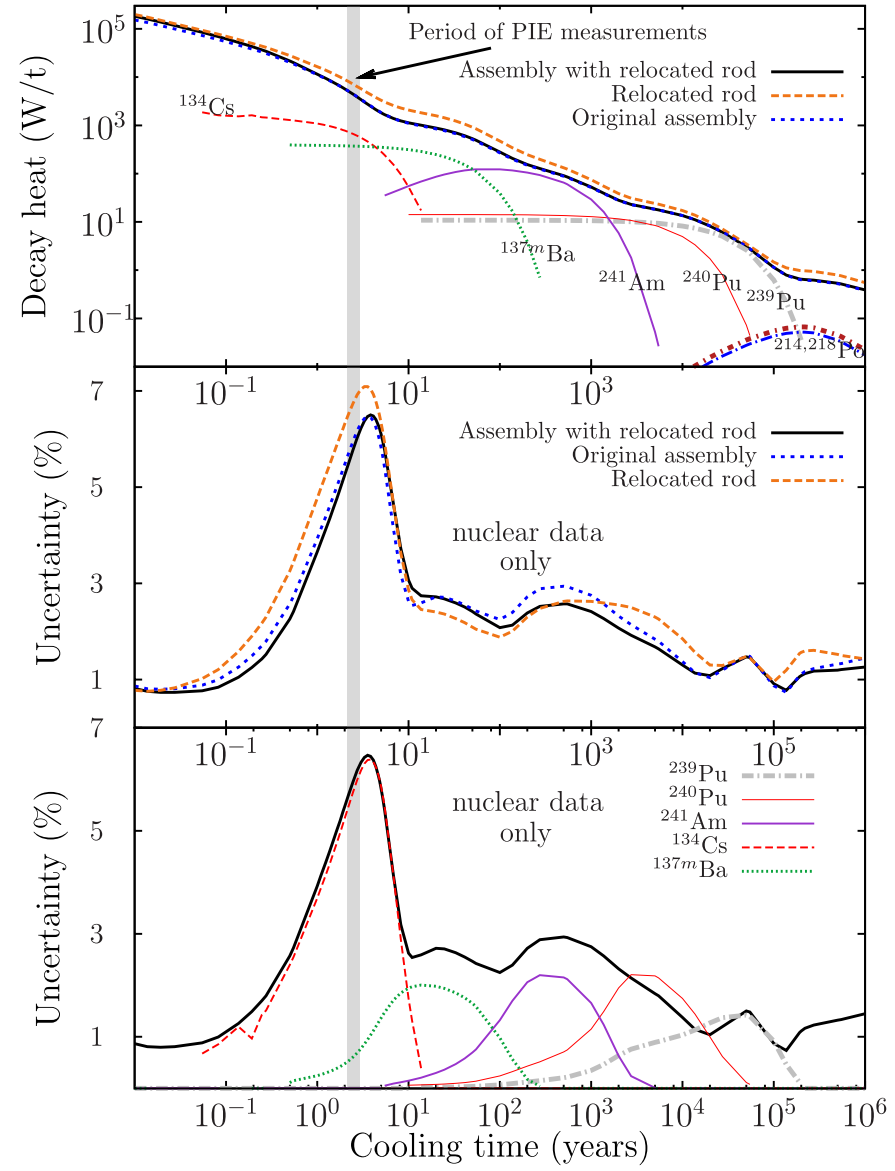

Fig. 8. Calculated decay heats for the assembly (with and without relocation) hosting the GU3 sample and the relocated rod (top); uncertainties due to nuclear data (middle and bottom figures), with the ENDF/B-VIII.0 library. The five most important contributors for the uncertainties are also presented.

in Table B.7, with a comparison for the GU1 sample). Whereas both total uncertainties for GU1 and GU3 are also similar, values for GU1 are systematically higher. As presented in Figure 8 bottom, the origins of such (small) differences depend on the cooling time and on the main involved isotopes. If the uncertainties in the case of the GU3 assembly are mainly due to five isotopes, more are involved for GU1: to an increased burnup value corresponds a larger number of isotopes influencing the uncertainties due to nuclear data.

Apart from this difference, the uncertainties due to nuclear data are mainly affected by the same isotopes for both sample cases: ${ }^{134} \mathrm{Cs},{ }^{137 m} \mathrm{Ba},{ }^{241} \mathrm{Am}$, and ${ }^{239,240} \mathrm{Pu}$. As explained for GU1, the JEFF-3.3 library provides smaller uncertainties (especially for the period where fission products are the main contributors). The partial contributions presented in Figure 8 do not show possible anti-correlations between uncertainties from different isotopes; this explains that the contribution from ${ }^{240} \mathrm{Pu}$ alone is larger than the total uncertainty $\left({ }^{240} \mathrm{Pu}\right.$ is anti-correlated with ${ }^{239} \mathrm{Pu}$ ).

Compared to other sources of uncertainties, nuclear data are still the predominant one; the moderator temperature (TMO) and the pin pitch also contribute in a non-negligible way to the total uncertainties for certain cooling periods. When combining all uncertainties (Tab. B.7), the RSS reaches a maximum of about $6 \%$ below 10 years of cooling. But such value does not taken into account possible isotopic biases as found in the previous section. Such isotope biases can be propagated to decay heat and expanded uncertainties are proposed in the following section.

Finally, uncertainties from decay data were not considered in this study (branching ratios, energy release, half-lives); this can impact the decay heat uncertainties at various cooling time.

\subsection{Expanded uncertainties}

As noticed, the concept of expanded uncertainties is useful to combine in a simple manner both biases and uncertainties. As for the isotopic contents, they are calculated for the decay heat and results are presented in Table B.8. Biases on decay heat are not known, as such decay heat was not measured. But biases on isotopic contents will reflect into biases for decay heat, proportionally to the importance of specific isotopes over cooling time. For instance, an underestimation for the concentration of ${ }^{239} \mathrm{Pu}$ can result in an underestimation for the decay heat, at least during the cooling time where ${ }^{239} \mathrm{Pu}$ is contributing to such decay heat. Therefore, the biases on the decay heat due to a number of isotopes are calculated taking into account the biases for isotopic contents, as well as their contributions as a function of cooling time.

The impacts of the ten most important isotopes are presented in Table B.8. For a number of them $\left({ }^{134} \mathrm{Cs}\right.$, ${ }^{244} \mathrm{Cm},{ }^{238,239,240} \mathrm{Pu},{ }^{241} \mathrm{Am},{ }^{234} \mathrm{U}$ and ${ }^{237} \mathrm{~Np}$ ), the impact of their difference between measurements and calculations is directly proportionally reported. For other isotopes such as ${ }^{106} \mathrm{Rh}$ and ${ }^{90} \mathrm{Y}$, only their parent nuclei are measured $\left({ }^{106} \mathrm{Ru}\right.$ and $\left.{ }^{90} \mathrm{Sr}\right)$. Assuming that the decay data for these isotopes are correct (direct beta decay), the biases from the parent nuclei is applied to their decay products.

As observed in Table B.8, the expanded uncertainties can be up to three times larger than the (direct) calculated uncertainties. Such values are for this assembly only, and different values were obtained for the GU1 assembly. It can also help to realize that direct calculated uncertainties are not the only contributors to the estimation of notmeasured decay heat. But this study, as well as the one for GU1, does not provide uncertainties in the case of SNF where no measurements were performed (isotopic compositions or decay heat). The question of decay heat uncertainties in the lack of measurements is therefore not answered in this study.

\section{Conclusion}

This work presents the analysis of the GU3 sample from the ARIANE program, in terms of nuclide inventory, as well as decay heat. Calculations are based on CASMO5 with a detailed irradiation history coming from core follow-up calculations. Results from various 
code versions and nuclear data libraries are presented. Some differences are observed for the nuclide inventory, explained by specific changes in the processed nuclear data libraries. Uncertainties due to nuclear data, operating conditions and manufacturing tolerances are also obtained, for both the isotopic inventory and decay heat. Results are presented in terms of expanded uncertainties, combining biases and uncertainties. Such consistent calculations between nuclide inventory and decay heat leads to a maximum uncertainty on the decay heat of less than 10\% below 100 years of cooling time.

This study complements our understanding of spent nuclear fuel characterization from a neutronics aspect, supported by national and international interests.

This work was partly supported by swiss nuclear, the association of the Swiss nuclear power station operators, with the COLOSS project. It was also partly funded by the European Union's Horizon 2020 Research and Innovation Programme under grant agreement No 847593.

\section{Author contribution statement}

All the co-authors have equally contributed to the calculations, analysis and writing. PSI has focused on creating the CASMO model, whereas the IRSN and Studsvik performed additional calculations.

\section{References}

1. J. Rhodes, K. Smith, D. Lee, CASMO-5 development and applications, in Proceedings of the PHYSOR-2006 conference, ANS Topical Meeting on Reactor Physics, Vancouver, BC, Canada, September 10-14, September 10-14 (2006), B144

2. E.L. Georgieva, J. Hykes, R.M. Ferrer, J. Rhodes, CASMO5 isotopic comparison to the ARIANE mixed-oxide pressurized water spent fuel measurements, in Proceedings of the PHYSOR 2018 conference: Reactor Physics paving the way towards more efficient systems, Cancun, Mexico, April 22-26, 2018 (2018) 1171

3. J. Li, D. Rochman, A. Vasiliev, H. Ferroukhi, J. Herrero, A. Pautz, M. Seidl, D. Janin, Bowing effects on isotopic concentrations for simplified PWR assemblies and full cores, Ann. Nucl. Energy 110, 1023 (2017)

4. T. Yamamoto, M. Suzuki, Y. Ando, H. Nagano, Validation of decay heat calculation results of ORIGEN2.2 and CASMO5 for light water reactor fuel, J. Nucl. Sci. Technol. 49, 910 (2012)

5. ARIANE International Programme Final Report. Belgonucléaire, AR2000/15 BN Ref. 0000253/221, Revision B, December (2000).

6. D. Rochman, A. Vasiliev, H. Ferroukhi, M. Hursin, Analysis for the ARIANE GU1 sample: nuclide inventory and decay heat, Ann. Nucl. Energy 160, 108359 (2021)

7. European Joint Programme on Radioactive Waste Management. EU H2020-Euratom-1.2 program, Grant agreement ID: 847593. https://cordis.europa.eu/project/id/847593

8. G. Radulescu, I.C. Gauld, G. Ilas, SCALE 5.1 Predictions of PWR Spent Nuclear Fuel Isotopic Compositions. Oak Ridge National Laboratory Report, ORNL/TM-2010/44 (2010)
9. H. Ferroukhi, K. Hofer, J.M. Hollard, A. Vasiliev, M.A. Zimmermann, Core Modelling and Analysis of the Swiss Nuclear Power Plants for Qualified R\&D Applications, in Proceedings of the Int. Conf. on the Physics of Reactors, PHYSOR'08, Interlaken, Switzerland (2008)

10. D. Rochman, A. Vasiliev, H. Ferroukhi, M. Pecchia, Consistent criticality and radiation studies of Swiss spent nuclear fuel: the $\mathrm{CS}_{2} \mathrm{M}$ approach, J. Hazard. Mater. 357, 384 (2018)

11. D. Rochman, A. Dokhane, A. Vasiliev, H. Ferroukhi, M. Hursin, Nuclear data uncertainties for Swiss BWR spent nuclear fuel characteristics, Eur. Phys. Jour. Plus 135, 233 (2020)

12. O. Leray, D. Rochman, P. Grimm, H. Ferroukhi, A. Vasiliev, M. Hursin, G. Perret, A. Pautz, Nuclear data uncertainty propagation on spent fuel nuclide compositions, Ann. Nucl. Energy 94, 603 (2016)

13. D.A. Brown et al., ENDF/B-VIII.0: The 8th Major Release of the Nuclear Reaction Data Library with CIELO-project Cross Sections, New Standards and Thermal Scattering Data, Nucl. Data Sheets 148, 1 (2018)

14. A.J.M. Plompen et al., The joint evaluated fission and fusion nuclear data library, JEFF-3.3, Eur. Phys. J. A 56, 181 (2020)

15. K. Shibata et al., JENDL-4.0: a new library for nuclear science and engineering, J. Nucl. Sci. Technol. 48, 1 (2011)

16. O. Leray, P. Grimm, M. Hursin, Ferroukhi, A. Pautz, Uncertainty Quantification of Spent Fuel Nuclide Compositions due to Cross-Sections, Decay Constants and Fission Yields", PHYSOR 2014 - The Role of Reactor Physics Toward a Sustainable Future, The Westin Miyako, Kyoto, Japan, September 28 - October 3, 2014, on CD-ROM (2014).

17. D. Siefman, M. Hursin, H. Sjostrand, G. Schnabel, D. Rochman, A. Pautz, Data assimilation of post-irradiation examination data for fission yields from GEF, Eur. Phys. J. N 6, 52 (2020)

18. S. Azzaoui, SCALE-6 fuel depletion analyses: Application to the ARIANE program, Master Thesis, SCK-CEN, Belgium, 2010

19. ASTM Standard C1769 - 15, Standard Practice for Analysis of Spent Nuclear Fuel to Determine Selected Isotopes and Estimate Fuel Burnup. ASTM International, West Conshohocken, PA (2003).

20. P. de Regge, R. Boden, Determination of Neodymium isotopes as burnup indicator of highly enriched $(\mathrm{U}, \mathrm{Pu}) \mathrm{O}_{2}$ LMFBR fuel, J. Radiol. Chem. 35, 173 (1977)

21. M.W Francis, C.F. Weber, M.T. Pigni, I.C. Gauld, Reactor fuel isotopics and code validation for nuclear applications, Oak Ridge National Laboratory Report ORNL/TM2014/464 (September 2014)

22. R.W. Mills, C.H. Zimmerman, R.G. Moore, Uncertainties on spent fuel inventories in the application of nuclear fuel cycles, in Proceedings of the CANDIDE workshop, Nuclear data needs for Generation-IV and accelerator driven systems, 16-18 October 2007 (2007) 131

23. R. Ichou, B. Dechenaux, On the validation of VESTA 2.2.0 using the ARIANE-GU3 sample, in Proceedings of the conference PHYSOR 2020: Transition to a Scalable Nuclear Future, Cambridge, United Kingdom, March 29-April 2, 2020 (2020)

24. O. Leray, H. Ferroukhi, M. Hursin, A. Vasiliev, D. Rochman, Methodology for core analyses with nuclear data uncertainty 
quantification and application to Swiss PWR operated cycles, Ann. Nucl. Energy 110, 547 (2017)

25. D. Rochman, A. Dokhane, A. Vasiliev, H. Ferroukhi, M. Hursin, Nuclear data uncertainties for core parameters based on Swiss BWR operated cycles, Ann. Nucl. Energy 148, 107727 (2020)

26. D. Rochman, A. Vasiliev, H. Ferroukhi, M. Seidl, J. Basualdo, Improvement of PIE analysis with a full core simulation: The U1 case, Ann. Nucl. Energy 148, 107706 (2020)

27. B. Ebiwonjumi, C. Kong, P. Zhang, A. Cherezov, D. Lee, Uncertainty quantification of PWR spent fuel due to nuclear data and modeling parameters, Nucl. Eng. Technol. (2020) in press

28. A. Rintala, Evaluating the effect of decay and fission yield data uncertainty on BWR spent nuclear fuel source term, in Proceedings of the International Conference Nuclear Energy for New Europe, Portoroz, Slovenia, September 7-10, 2020 (2020)

29. G. Ilas, H. Liljenfeldt, Decay heat uncertainty for BWR used fuel due to modeling and nuclear data uncertainties, Nucl. Eng. Des. 319, 176 (2017)

30. I.C. Gauld, G. Ilas, G. Radulescu, Uncertainties in predicted isotopic compositions for high burnup PWR spent nuclear fuel, Oak Ridge National Laboratory Report ORNL/TM2010/41, NUREG/CR-7012, January 2011

31. S.D. Phillips, K.R. Eberhardt, B. Parry, Guidelines for expressing the uncertainty of measurement results containing uncorrected bias, J. Res. Natl. Inst. Stand. Technol. 102, $577(1997)$

32. Guide to the Expression of Uncertainty in Measurement. JCGM 100:2008, International Organization for Standardisation. Geneva, Switzerland.

Cite this article as: Dimitri Rochman, Alexander Vasiliev, Hakim Ferroukhi, Mathieu Hursin, Raphaelle Ichou, Julien Taforeau, Teodosi Simeonov, Analysis for the ARIANE GU3 sample: nuclide inventory and decay heat, EPJ Nuclear Sci. Technol. 7, 14 (2021) 


\section{Appendix A: Tabulated measured and recommended nuclide inventory}

In the following, the isotopic compositions from the ARIANE report (measured and recommended), as well as the recommended values from reference [8] are presented. In reference [8] the recommended values are given in the units of $\mathrm{g} / \mathrm{gU}_{\text {initial }}$ and are converted to $\mathrm{mg} / \mathrm{gU}$ at the time of measurements using equation (10) of the same report. Some of the recommended concentrations in the ORNL report are provided at the end of life (EOL), which is not convenient for their usage in the present work. In Table A.1, they are indicated with $\mathrm{a}^{*}$, and are given at the time of measurements, as these values can be directly found in the ARIANE report. Consequently, in these cases, only values in $\mathrm{mg} / \mathrm{gU}$ are reported.

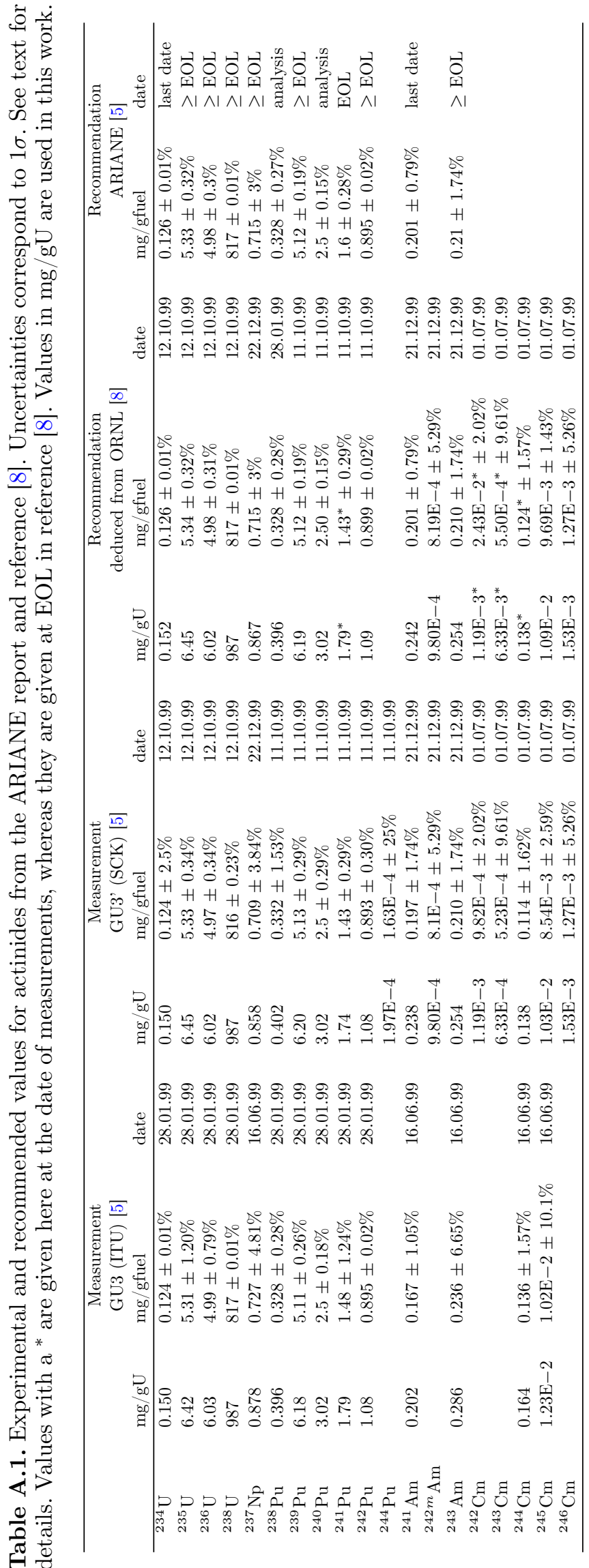




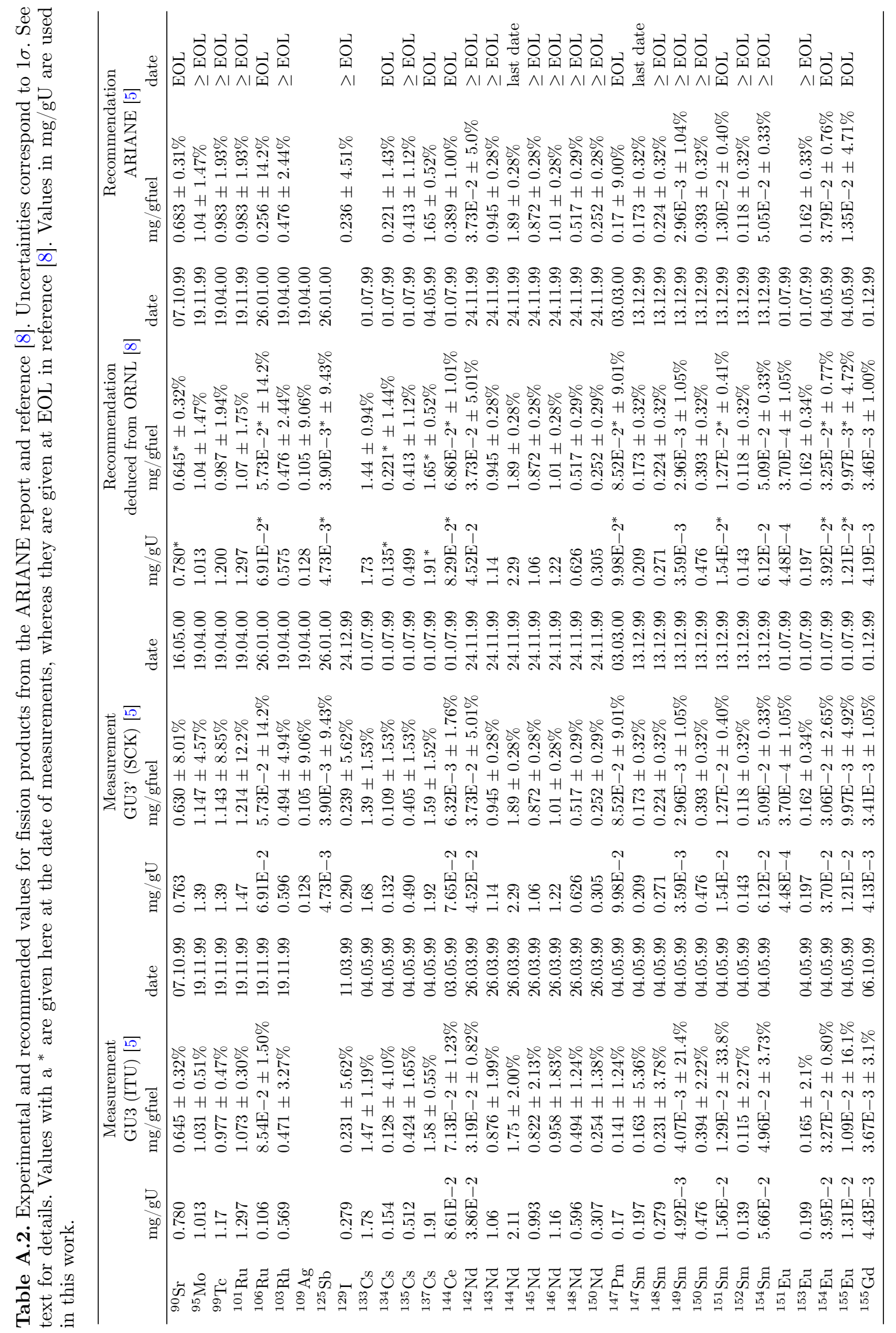




\section{Appendix B: Tabulated calculated nuclide inventory and uncertainties}

Table B.1. Nominal C/E-1 values and experimental uncertainties in\% (as one standard deviation) for the GU3 and GU3' samples. Calculations are performed with CASMO5 version 2.03 and the e7r1.201.586.bin library, except for ${ }^{151} \mathrm{Eu}$ (CASMO5 version 2.13 with the e7r1.202.586.bin library).

\begin{tabular}{|c|c|c|c|c|c|c|c|}
\hline & \multicolumn{2}{|c|}{ Measurement } & \multirow{2}{*}{$\begin{array}{l}\text { Recommendation } \\
\text { reference [8] }\end{array}$} & & \multicolumn{2}{|c|}{ Measurement } & \multirow{2}{*}{$\begin{array}{l}\text { Recommendation } \\
\text { reference [8] }\end{array}$} \\
\hline & $\begin{array}{l}\text { GU3 } \\
\text { (ITU) }\end{array}$ & $\begin{array}{l}\text { GU3' } \\
\text { (SCK) }\end{array}$ & & & $\begin{array}{l}\text { GU3 } \\
\text { (ITU) }\end{array}$ & $\begin{array}{l}\text { GU3' } \\
\text { (SCK) }\end{array}$ & \\
\hline${ }^{234} \mathrm{U}$ & +43 & +44 & +43 & ${ }^{235} \mathrm{U}$ & +3.4 & +3.0 & +3.0 \\
\hline${ }^{236} \mathrm{U}$ & +0.6 & +0.7 & +0.7 & ${ }^{238} \mathrm{U}$ & +0.0 & +0.0 & +0.0 \\
\hline${ }^{237} \mathrm{~Np}$ & -16 & -14 & -15 & ${ }^{238} \mathrm{Pu}$ & -3.7 & -5.8 & -3.7 \\
\hline${ }^{239} \mathrm{Pu}$ & -0.1 & -0.4 & -0.3 & ${ }^{240} \mathrm{Pu}$ & +2.1 & +2.2 & +2.2 \\
\hline${ }^{241} \mathrm{Pu}$ & -2.6 & -3.1 & +5.0 & ${ }^{242} \mathrm{Pu}$ & -0.0 & -0.0 & -0.9 \\
\hline${ }^{244} \mathrm{Pu}$ & - & -73 & - & ${ }^{241} \mathrm{Am}$ & +13 & +14 & +12 \\
\hline${ }^{242 m} \mathrm{Am}$ & - & +8.5 & +8.5 & ${ }^{243} \mathrm{Am}$ & -12 & -1.0 & -1.0 \\
\hline${ }^{242} \mathrm{Cm}$ & - & -6.1 & -6.1 & ${ }^{243} \mathrm{Cm}$ & - & +38 & +38 \\
\hline${ }^{244} \mathrm{Cm}$ & -25 & -11 & -11 & ${ }^{245} \mathrm{Cm}$ & -23 & -8.6 & -11 \\
\hline${ }^{246} \mathrm{Cm}$ & - & -20 & -20 & & & & \\
\hline${ }^{90} \mathrm{Sr}$ & +4.7 & +5.4 & +4.7 & ${ }^{95} \mathrm{Mo}$ & +22 & -11 & +22 \\
\hline${ }^{99} \mathrm{Tc}$ & +8.6 & -8.5 & +6.0 & ${ }^{101} \mathrm{Ru}$ & -0.5 & -12 & -0.5 \\
\hline${ }^{106} \mathrm{Ru}$ & -48 & -3.6 & -3.6 & ${ }^{103} \mathrm{Rh}$ & +29 & +23 & +28 \\
\hline${ }^{109} \mathrm{Ag}$ & - & -35 & -35 & ${ }^{125} \mathrm{Sb}$ & - & +63 & +63 \\
\hline${ }^{129} \mathrm{I}$ & -14 & -17 & - & ${ }^{133} \mathrm{Cs}$ & +1.2 & +7.2 & +4.1 \\
\hline${ }^{134} \mathrm{Cs}$ & -11 & -1.6 & -3.8 & ${ }^{135} \mathrm{Cs}$ & +0.8 & +5.4 & +3.5 \\
\hline${ }^{137} \mathrm{Cs}$ & +2.6 & +1.7 & +2.6 & ${ }^{144} \mathrm{Ce}$ & +6.0 & +3.9 & -4.1 \\
\hline${ }^{147} \mathrm{Pm}$ & -10 & +23 & +23 & ${ }^{142} \mathrm{Nd}$ & +18 & +0.5 & +0.5 \\
\hline${ }^{143} \mathrm{Nd}$ & +11 & +3.1 & +3.1 & ${ }^{144} \mathrm{Nd}$ & +6.0 & -0.4 & -0.4 \\
\hline${ }^{145} \mathrm{Nd}$ & +7.9 & +1.1 & +1.1 & ${ }^{146} \mathrm{Nd}$ & +4.7 & -0.5 & -0.5 \\
\hline${ }^{148} \mathrm{Nd}$ & +5.5 & +0.5 & +0.5 & ${ }^{150} \mathrm{Nd}$ & -0.8 & -0.1 & -0.1 \\
\hline${ }^{147} \mathrm{Sm}$ & +4.6 & +9.2 & +9.2 & ${ }^{148} \mathrm{Sm}$ & -6.7 & -4.0 & -4.0 \\
\hline${ }^{149} \mathrm{Sm}$ & -20 & +9.6 & +9.6 & ${ }^{150} \mathrm{Sm}$ & +5.6 & +5.6 & +5.6 \\
\hline${ }^{151} \mathrm{Sm}$ & -0.7 & +0.1 & +0.1 & ${ }^{152} \mathrm{Sm}$ & +9.3 & +6.2 & +6.2 \\
\hline${ }^{154} \mathrm{Sm}$ & +19 & +10 & +10 & ${ }^{151} \mathrm{Eu}$ & - & +57 & - \\
\hline${ }^{153} \mathrm{Eu}$ & -2.7 & -1.7 & -1.7 & ${ }^{154} \mathrm{Eu}$ & +0.6 & +6.0 & +1.3 \\
\hline${ }^{155} \mathrm{Eu}$ & -13 & -8.3 & -14 & ${ }^{155} \mathrm{Gd}$ & +0.0 & +14 & +12 \\
\hline
\end{tabular}


Table B.2. Uncertainties $\Delta \mathrm{C}$ from nuclear data libraries for the GU3' sample for the actinide isotopic concentrations (CASMO5 v2.03 calculations). Numbers in italics are for the GU1 sample. For the $5^{\text {th }}$ and $6^{\text {th }}$ columns, see Section 5.2 for details. All values are in\%.

\begin{tabular}{llllll}
\hline & $\begin{array}{l}\text { ENDF/B-VIII.0 } \\
\text { GU3' }(G U 1)\end{array}$ & $\begin{array}{l}\text { JEFF-3.3 } \\
\text { GU3' }(G U 1)\end{array}$ & $\begin{array}{l}\text { JENDL-4.0 } \\
\text { GU3' }(G U 1)\end{array}$ & $\begin{array}{l}C_{\max }-C_{\min } \\
\text { GU3 }{ }^{\prime} \\
12 \text { cases }\end{array}$ & $\begin{array}{l}\sigma_{\text {CASMO5 }} \\
\text { GU3' } \\
12 \text { cases }\end{array}$ \\
\hline${ }^{234} \mathrm{U}$ & $2.3(0.6)$ & $2.2(2.8)$ & $7.9(9.9)$ & 5.0 & 1.2 \\
${ }^{235} \mathrm{U}$ & $1.2(2.3)$ & $1.6(3.2)$ & $1.8(4.1)$ & 4.5 & 1.5 \\
${ }^{236} \mathrm{U}$ & $0.8(0.5)$ & $1.7(1.6)$ & $1.2(1.3)$ & 2.5 & 0.8 \\
${ }^{238} \mathrm{U}$ & $0.0(0.0)$ & $0.0(0.0)$ & $0.0(0.0)$ & 0.0 & 0.0 \\
${ }^{237} \mathrm{~Np}$ & $3.3(-)$ & $3.9(-)$ & $4.0(-)$ & 2.0 & 0.6 \\
${ }^{238} \mathrm{Pu}$ & $4.8(2.7)$ & $9.4(13)$ & $7.0(9.4)$ & 7.9 & 2.6 \\
${ }^{239} \mathrm{Pu}$ & $1.8(1.9)$ & $1.7(1.9)$ & $2.2(2.6)$ & 2.0 & 0.5 \\
${ }^{240} \mathrm{Pu}$ & $4.3(4.2)$ & $2.5(2.5)$ & $4.4(4.9)$ & 2.3 & 0.7 \\
${ }^{241} \mathrm{Pu}$ & $3.2(3.4)$ & $3.1(3.5)$ & $3.4(3.9)$ & 2.9 & 0.8 \\
${ }^{242} \mathrm{Pu}$ & $4.8(5.0)$ & $8.5(8.6)$ & $8.6(8.7)$ & 3.6 & 1.0 \\
${ }^{244} \mathrm{Pu}$ & $8.9(8.1)$ & $8.1(8.2)$ & $9.2(8.7)$ & 28 & 13 \\
${ }^{241} \mathrm{Am}$ & $3.4(3.5)$ & $3.1(3.6)$ & $3.9(4.4)$ & 4.6 & 1.5 \\
${ }^{242 m} \mathrm{Am}$ & $3.8(4.0)$ & $3.2(4.2)$ & $4.5(4.4)$ & 4.0 & 1.5 \\
${ }^{243} \mathrm{Am}$ & $8.5(7.5)$ & $7.7(7.6)$ & $9.0(8.7)$ & 6.9 & 2.0 \\
${ }^{242} \mathrm{Cm}$ & $3.6(3.3)$ & $2.7(3.0)$ & $4.1(3.5)$ & 6.5 & 1.8 \\
${ }^{243} \mathrm{Cm}$ & $11(11)$ & $16(17)$ & $12(12)$ & 31 & 8.5 \\
${ }^{244} \mathrm{Cm}$ & $9.7(8.6)$ & $9.3(9.0)$ & $10(9.7)$ & 12 & 3.1 \\
${ }^{245} \mathrm{Cm}$ & $15(13)$ & $14(14)$ & $15(15)$ & 56 & 12 \\
${ }^{246} \mathrm{Cm}$ & $24(13)$ & $21(21)$ & $24(24)$ & 56 & 16 \\
\hline
\end{tabular}


Table B.3. Same as Table B.2 but for fission products.

\begin{tabular}{|c|c|c|c|c|c|}
\hline & $\begin{array}{l}\text { ENDF/B-VIII.0 } \\
\text { GU3' (GU1) }\end{array}$ & $\begin{array}{l}\text { JEFF-3.3 } \\
\text { GU3' (GU1) }\end{array}$ & $\begin{array}{l}\text { JENDL- } 4.0 \\
\text { GU3' (GU1) }\end{array}$ & $\begin{array}{l}\frac{C_{\max }-C_{\min }}{E} \\
\mathrm{GU} 3^{\frac{P}{}} \\
12 \text { cases }\end{array}$ & $\begin{array}{l}\sigma_{\text {CASMO5 }} \\
\text { GU3' } \\
12 \text { cases }\end{array}$ \\
\hline${ }^{90} \mathrm{Sr}$ & $0.7(0.7)$ & 1.4 (1.3) & 0.7 (0.7) & 2.8 & 0.6 \\
\hline${ }^{95} \mathrm{Mo}$ & $0.9(0.8)$ & $0.7(0.7)$ & $0.9(0.8)$ & 1.2 & 2.9 \\
\hline${ }^{99} \mathrm{Tc}$ & $1.4(1.6)$ & $0.8(0.8)$ & $1.6(1.8)$ & 1.2 & 0.4 \\
\hline${ }^{101} \mathrm{Ru}$ & 2.8 (3.2) & $0.9(1.0)$ & 3.1 (3.4) & 1.3 & 0.5 \\
\hline${ }^{106} \mathrm{Ru}$ & $1.5(1.4)$ & $1.7(1.8)$ & $1.5(1.4)$ & 4.0 & 0.5 \\
\hline${ }^{103} \mathrm{Rh}$ & 1.7 (2.0) & $1.7(1.8)$ & $1.3(1.5)$ & 3.8 & 1.0 \\
\hline${ }^{109} \mathrm{Ag}$ & 21 (21) & $4.4(4.5)$ & $20(19)$ & 43 & 13 \\
\hline${ }^{125} \mathrm{Sb}$ & $18(18)$ & $27(30)$ & 30 (32) & 36 & 10 \\
\hline${ }^{129} \mathrm{I}$ & $3.0(-)$ & $6.1(-)$ & $3.5(-)$ & 5.0 & 1.8 \\
\hline${ }^{133} \mathrm{Cs}$ & 28 (27) & $2.3(2.4)$ & 30 (29) & 3.3 & 0.8 \\
\hline${ }^{134} \mathrm{Cs}$ & 29 (27) & $4.6(4.3)$ & 30 (28) & 5.8 & 1.8 \\
\hline${ }^{135} \mathrm{Cs}$ & $7.1(5.0)$ & 20 (19) & $7.6(5.2)$ & 4.0 & 1.3 \\
\hline${ }^{137} \mathrm{Cs}$ & 6.7 (6.2) & $3.6(3.5)$ & $6.9(6.5)$ & 1.6 & 0.4 \\
\hline${ }^{144} \mathrm{Ce}$ & $0.4(0.4)$ & $0.6(0.6)$ & $0.5(0.4)$ & 1.3 & 0.3 \\
\hline${ }^{147} \mathrm{Pm}$ & 2.5 (2.6) & 1.2 (1.3) & $1.3(1.5)$ & 2.8 & 0.8 \\
\hline${ }^{142} \mathrm{Nd}$ & 5.1 (4.2) & $5.0(4.3)$ & 0.8 (1.4) & 2.0 & 0.7 \\
\hline${ }^{143} \mathrm{Nd}$ & $2.0(2.4)$ & $3.6(5.1)$ & 0.9 (1.4) & 2.1 & 0.7 \\
\hline${ }^{144} \mathrm{Nd}$ & $1.2(0.9)$ & $2.2(1.9)$ & $0.4(0.5)$ & 1.6 & 0.5 \\
\hline${ }^{145} \mathrm{Nd}$ & 2.0 (2.3) & $0.9(1.0)$ & $0.4(0.5)$ & 1.8 & 0.5 \\
\hline${ }^{146} \mathrm{Nd}$ & $1.7(1.7)$ & $0.7(0.8)$ & $0.3(0.4)$ & 1.3 & 0.4 \\
\hline${ }^{148} \mathrm{Nd}$ & $0.4(0.4)$ & $0.6(0.6)$ & $0.4(0.4)$ & 2.2 & 0.6 \\
\hline${ }^{150} \mathrm{Nd}$ & $0.4(0.4)$ & $0.9(0.9)$ & $0.5(0.5)$ & 1.8 & 0.4 \\
\hline${ }^{147} \mathrm{Sm}$ & $2.2(2.5)$ & 1.2 (1.3) & 1.2 (1.4) & 2.1 & 0.7 \\
\hline${ }^{148} \mathrm{Sm}$ & $1.8(1.5)$ & $1.9(2.0)$ & $1.0(1.0)$ & 1.9 & 0.6 \\
\hline${ }^{149} \mathrm{Sm}$ & $1.7(1.7)$ & $3.5(3.4)$ & $1.6(1.8)$ & 4.8 & 1.2 \\
\hline${ }^{150} \mathrm{Sm}$ & $1.2(1.1)$ & $1.3(1.5)$ & $1.0(1.0)$ & 9.5 & 3.0 \\
\hline${ }^{151} \mathrm{Sm}$ & 2.7 (2.4) & 12 (13) & 2.0 (2.1) & 17 & 5.4 \\
\hline${ }^{152} \mathrm{Sm}$ & $2.6(2.5)$ & $3.8(3.9)$ & $1.2(1.1)$ & 13 & 4.4 \\
\hline${ }^{154} \mathrm{Sm}$ & $1.6(1.7)$ & $7.3(7.8)$ & 1.7 (1.7) & 7.9 & 2.0 \\
\hline${ }^{153} \mathrm{Eu}$ & 3.3 (3.3) & 2.1 (2.1) & 1.1 (1.1) & 10 & 3.5 \\
\hline${ }^{154} \mathrm{Eu}$ & $2.8(1.9)$ & 2.3 (2.2) & $1.3(1.5)$ & 8.5 & 2.6 \\
\hline${ }^{155} \mathrm{Eu}$ & 24 (19) & 24 (20) & 1.1 (1.0) & 3.6 & 1.0 \\
\hline${ }^{155} \mathrm{Gd}$ & 23 (19) & 23 (20) & 1.1 (1.0) & 4.6 & 1.2 \\
\hline
\end{tabular}


Table B.4. Summary of all uncertainties in\% (or $1 \sigma$ ) for the GU3' sample considered in this study for actinides. For nuclear data (ND), the range from Tables B.2 and B.3 is presented here. The "Sum" column corresponds to $\sqrt{\sum_{i} \Delta^{2}\left(C_{i}\right)}$ for calculated uncertainties. The sum for the GU1 sample is also indicated (without the systematic effect of $2 \%$ for the mass balance). See text for the description of the columns.

\begin{tabular}{llllllllllll}
\hline & $\begin{array}{l}\text { ND } \\
\text { min-max }\end{array}$ & TFU & TMO & BOR & RAD & $\begin{array}{l}\text { ENR } \\
+ \text { DEN }\end{array}$ & $\begin{array}{l}\text { (X-Y) } \\
\text { DEP }\end{array}$ & PITCH & $\begin{array}{l}\text { Sum } \\
\min -\max \end{array}$ & $\begin{array}{l}\text { Sum } \\
\min -\max \end{array}$ \\
\hline${ }^{234} \mathrm{U}$ & $2.3-7.9$ & 0.0 & 0.3 & 0.0 & 0.1 & 0.1 & 0.2 & 0.2 & 0.5 & $2.3-7.9$ & $0.9-10$ \\
${ }^{235} \mathrm{U}$ & $1.2-1.8$ & 0.2 & 1.8 & 0.0 & 0.6 & 0.6 & 1.0 & 0.4 & 1.1 & $2.8-3.1$ & $5.4-6.3$ \\
${ }^{236} \mathrm{U}$ & $0.8-1.7$ & 0.0 & 0.3 & 0.0 & 0.0 & 0.2 & 0.1 & 0.1 & 0.1 & $0.9-1.7$ & $0.7-1.7$ \\
${ }^{238} \mathrm{U}$ & 0.0 & 0.0 & 0.0 & 0.0 & 0.0 & 0.0 & 0.0 & 0.0 & 0.0 & $0.0-0.0$ & 0.0 \\
${ }^{237} \mathrm{~Np}$ & $3.3-4.0$ & 0.1 & 0.9 & 0.0 & 0.2 & 0.3 & 0.2 & 0.2 & 1.1 & $3.7-4.2$ & - \\
${ }^{238} \mathrm{Pu}$ & $4.8-9.4$ & 0.0 & 1.8 & 0.0 & 0.2 & 0.4 & 0.4 & 0.4 & 2.0 & $5.6-10$ & $3.5-13$ \\
${ }^{239} \mathrm{Pu}$ & $1.7-2.2$ & 0.2 & 1.6 & 0.0 & 0.2 & 0.1 & 0.4 & 0.0 & 1.6 & $2.9-3.2$ & $2.8-3.3$ \\
${ }^{240} \mathrm{Pu}$ & $2.5-4.4$ & 0.1 & 1.0 & 0.0 & 0.1 & 0.1 & 0.2 & 0.1 & 0.6 & $2.8-4.5$ & $2.6-5.0$ \\
${ }^{241} \mathrm{Pu}$ & $3.1-3.4$ & 0.2 & 1.8 & 0.0 & 0.2 & 0.3 & 0.2 & 0.1 & 1.5 & $3.8-4.2$ & $4.0-4.5$ \\
${ }^{242} \mathrm{Pu}$ & $4.8-8.6$ & 0.1 & 1.0 & 0.0 & 0.5 & 0.7 & 0.6 & 0.4 & 0.9 & $5.1-8.7$ & $5.2-8.8$ \\
${ }^{244} \mathrm{Pu}$ & $8.1-9.2$ & 0.1 & 1.8 & 0.0 & 0.7 & 0.9 & 1.1 & 0.7 & 1.9 & $8.7-9.7$ & $8.7-9.3$ \\
${ }^{241} \mathrm{Am}$ & $3.1-3.9$ & 0.2 & 1.8 & 0.0 & 0.2 & 0.3 & 0.3 & 0.1 & 2.7 & $4.5-5.1$ & $4.2-5.0$ \\
${ }^{242 m} \mathrm{Am}$ & $3.2-4.5$ & 0.3 & 3.2 & 0.1 & 0.4 & 0.3 & 0.7 & 0.2 & 3.6 & $5.8-6.6$ & $6.3-6.6$ \\
${ }^{243} \mathrm{Am}$ & $7.7-9.0$ & 0.1 & 1.3 & 0.0 & 0.6 & 0.7 & 0.7 & 0.5 & 1.7 & $8.1-9.3$ & $7.7-9.0$ \\
${ }^{242} \mathrm{Cm}$ & $2.7-4.1$ & 0.1 & 1.8 & 0.0 & 0.3 & 0.5 & 0.2 & 0.3 & 1.6 & $3.7-4.8$ & $3.4-3.9$ \\
${ }^{243} \mathrm{Cm}$ & $11-16$ & 0.1 & 2.6 & 0.1 & 0.3 & 0.6 & 0.3 & 0.5 & 2.7 & $12-16$ & $12-16$ \\
${ }^{244} \mathrm{Cm}$ & $9.3-10$ & 0.1 & 2.4 & 0.1 & 0.6 & 0.9 & 1.0 & 0.8 & 3.1 & $10-11$ & $9.3-10$ \\
${ }^{245} \mathrm{Cm}$ & $14-15$ & 0.1 & 4.9 & 0.1 & 0.5 & 0.9 & 1.1 & 0.9 & 4.8 & $16-17$ & $14-16$ \\
${ }^{246} \mathrm{Cm}$ & $21-24$ & 0.1 & 2.9 & 0.1 & 0.9 & 1.2 & 1.6 & 1.2 & 4.1 & $21-25$ & $14-24$ \\
\hline
\end{tabular}


Table B.5. Same as Table B.4, but for fission products.

\begin{tabular}{|c|c|c|c|c|c|c|c|c|c|c|c|}
\hline & $\begin{array}{l}\text { ND } \\
\min -\max \end{array}$ & TFU & TMO & BOR & RAD & $\begin{array}{l}\text { ENR } \\
+ \text { DEN }\end{array}$ & $(\mathrm{X}-\mathrm{Y})$ & DEP & PITCH & $\begin{array}{l}\text { Sum } \\
\text { min-max }\end{array}$ & $\begin{array}{l}\operatorname{Sum}_{\mathrm{GU} 1} \\
\min -\max \end{array}$ \\
\hline${ }^{90} \mathrm{Sr}$ & $0.7-1.4$ & 0.0 & 0.1 & 0.0 & 0.2 & 0.2 & 0.2 & 0.1 & 0.3 & $0.8-1.4$ & $0.9-1.5$ \\
\hline${ }^{95} \mathrm{Mo}$ & $0.7-0.9$ & 0.0 & 0.1 & 0.0 & 0.2 & 0.2 & 0.2 & 0.2 & 0.5 & $0.9-1.1$ & $0.9-1.0$ \\
\hline${ }^{99} \mathrm{Tc}$ & $0.8-1.6$ & 0.0 & 0.2 & 0.0 & 0.2 & 0.2 & 0.2 & 0.2 & 0.3 & $0.9-1.7$ & $1.0-1.7$ \\
\hline${ }^{101} \mathrm{Ru}$ & $0.9-3.1$ & 0.0 & 0.2 & 0.0 & 0.2 & 0.3 & 0.2 & 0.2 & 0.4 & $1.1-3.1$ & $1.3-3.5$ \\
\hline${ }^{106} \mathrm{Ru}$ & $1.5-1.7$ & 0.0 & 0.7 & 0.0 & 0.3 & 0.4 & 0.3 & 0.2 & 0.4 & $1.8-1.9$ & $1.6-2.0$ \\
\hline${ }^{103} \mathrm{Rh}$ & $1.3-1.7$ & 0.1 & 0.5 & 0.0 & 0.2 & 0.2 & 0.1 & 0.1 & 0.4 & $1.4-1.8$ & $1.6-2.1$ \\
\hline${ }^{109} \mathrm{Ag}$ & $4.4-21$ & 0.1 & 0.9 & 0.0 & 0.3 & 0.4 & 0.3 & 0.3 & 0.9 & $4.6-21$ & $4.7-21$ \\
\hline${ }^{125} \mathrm{Sb}$ & $18.0-30$ & 0.0 & 0.5 & 0.0 & 0.2 & 0.3 & 0.3 & 0.2 & 0.4 & $18-30$ & $18-32$ \\
\hline${ }^{129} \mathrm{I}$ & $3.0-6.1$ & 0.0 & 0.5 & 0.0 & 0.2 & 0.3 & 0.2 & 0.2 & 0.6 & $3.1-6.1$ & - \\
\hline${ }^{133} \mathrm{Cs}$ & $2.3-30$ & 0.0 & 0.2 & 0.0 & 0.2 & 0.2 & 0.2 & 0.2 & 0.3 & $2.3-30$ & $2.4-29$ \\
\hline${ }^{134} \mathrm{Cs}$ & $4.6-30$ & 0.0 & 1.0 & 0.0 & 0.3 & 0.4 & 0.5 & 0.3 & 1.1 & $4.9-30$ & $4.5-28$ \\
\hline${ }^{135} \mathrm{Cs}$ & $7.1-20$ & 0.1 & 1.6 & 0.0 & 0.1 & 0.2 & 0.2 & 0.2 & 1.6 & $7.5-20$ & $5.3-19$ \\
\hline${ }^{137} \mathrm{Cs}$ & $3.6-6.9$ & 0.0 & 0.2 & 0.0 & 0.2 & 0.3 & 0.3 & 0.2 & 0.5 & $3.6-6.9$ & $3.6-6.5$ \\
\hline${ }^{144} \mathrm{Ce}$ & $0.4-0.6$ & 0.0 & 0.4 & 0.0 & 0.2 & 0.2 & 0.3 & 0.0 & 0.6 & $0.9-1.0$ & $0.9-1.0$ \\
\hline${ }^{142} \mathrm{Nd}$ & $0.8-5.1$ & 0.1 & 0.4 & 0.0 & 0.4 & 0.5 & 0.7 & 0.4 & 1.0 & $1.7-5.3$ & $2.5-4.7$ \\
\hline${ }^{143} \mathrm{Nd}$ & $0.9-3.6$ & 0.1 & 0.7 & 0.0 & 0.1 & 0.2 & 0.0 & 0.1 & 0.5 & $1.3-3.7$ & $1.9-5.2$ \\
\hline${ }^{144} \mathrm{Nd}$ & $0.4-2.2$ & 0.0 & 0.4 & 0.0 & 0.3 & 0.3 & 0.5 & 0.3 & 0.7 & $1.1-2.4$ & $1.1-2.2$ \\
\hline${ }^{145} \mathrm{Nd}$ & $0.4-2.0$ & 0.0 & 0.2 & 0.0 & 0.2 & 0.2 & 0.2 & 0.1 & 0.3 & $0.7-2.0$ & $0.7-2.4$ \\
\hline${ }^{146} \mathrm{Nd}$ & $0.3-1.7$ & 0.0 & 0.2 & 0.0 & 0.2 & 0.3 & 0.3 & 0.2 & 0.6 & $0.8-1.9$ & $1.0-1.9$ \\
\hline${ }^{148} \mathrm{Nd}$ & $0.4-0.6$ & 0.0 & 0.2 & 0.0 & 0.2 & 0.3 & 0.3 & 0.2 & 0.5 & $0.9-0.9$ & $0.9-1.0$ \\
\hline${ }^{150} \mathrm{Nd}$ & $0.4-0.9$ & 0.0 & 0.4 & 0.0 & 0.2 & 0.3 & 0.3 & 0.2 & 0.6 & $1.0-1.2$ & $0.9-1.2$ \\
\hline${ }^{147} \mathrm{Pm}$ & $1.2-2.5$ & 0.0 & 0.5 & 0.0 & 0.1 & 0.1 & 0.1 & 0.0 & 0.4 & $1.4-2.6$ & $1.4-2.6$ \\
\hline${ }^{147} \mathrm{Sm}$ & $1.2-2.2$ & 0.0 & 0.5 & 0.0 & 0.1 & 0.1 & 0.1 & 0.1 & 0.5 & $1.4-2.4$ & $1.3-2.5$ \\
\hline${ }^{148} \mathrm{Sm}$ & $1.0-1.9$ & 0.0 & 0.6 & 0.0 & 0.2 & 0.4 & 0.4 & 0.3 & 1.1 & $1.7-2.4$ & $1.6-2.4$ \\
\hline${ }^{149} \mathrm{Sm}$ & $1.6-3.5$ & 0.1 & 2.0 & 0.0 & 0.1 & 0.1 & 0.2 & 0.0 & 2.0 & $3.3-4.5$ & $2.5-3.9$ \\
\hline${ }^{150} \mathrm{Sm}$ & $1.0-1.3$ & 0.0 & 0.3 & 0.0 & 0.2 & 0.3 & 0.3 & 0.2 & 0.5 & $1.3-1.5$ & $1.2-1.7$ \\
\hline${ }^{151} \mathrm{Sm}$ & $2.0-12$ & 0.1 & 3.0 & 0.0 & 0.2 & 0.1 & 0.3 & 0.1 & 1.7 & $4.0-12$ & $3.7-13$ \\
\hline${ }^{152} \mathrm{Sm}$ & $1.2-3.8$ & 0.0 & 1.0 & 0.0 & 0.2 & 0.3 & 0.2 & 0.1 & 0.4 & $1.6-4.0$ & $1.5-4.0$ \\
\hline${ }^{154} \mathrm{Sm}$ & $1.7-7.3$ & 0.0 & 0.6 & 0.0 & 0.3 & 0.4 & 0.3 & 0.3 & 0.7 & $2.0-7.4$ & $2.0-7.9$ \\
\hline${ }^{153} \mathrm{Eu}$ & $1.1-3.3$ & 0.0 & 0.3 & 0.0 & 0.2 & 0.3 & 0.2 & 0.2 & 0.6 & $1.3-3.4$ & $1.3-3.4$ \\
\hline${ }^{154} \mathrm{Eu}$ & $1.3-2.8$ & 0.0 & 1.6 & 0.0 & 0.2 & 0.3 & 0.3 & 0.2 & 1.7 & $2.7-3.7$ & $2.3-2.8$ \\
\hline${ }^{155} \mathrm{Eu}$ & $1.1-24$ & 0.0 & 0.3 & 0.0 & 0.3 & 0.3 & 0.3 & 0.3 & 0.7 & $1.5-24$ & $1.3-19$ \\
\hline${ }^{155} \mathrm{Gd}$ & $1.1-23$ & 0.0 & 0.4 & 0.0 & 0.3 & 0.3 & 0.3 & 0.2 & 3.8 & $4.0-24$ & $1.3-20$ \\
\hline
\end{tabular}


Table B.6. Expanded estimated uncertainties $\Delta_{\text {expanded }}$ on isotopic concentrations for GU3', taking into account the calculation bias and the experimental and calculated uncertainties. $\Delta \mathrm{C}_{\max }$ come from the nuclear data library leading to the highest nuclear data uncertainty (either ENDF/B-VIII.0, JEFF-3.3 or JENDL-4.0). Three combination methods are presented: $\mathrm{RSSu}_{c}$, $\operatorname{RSS} U$ (being equal to $\mathrm{RSSu}_{c}$ for $1 \sigma$ ), and $\mathrm{SUM} U$.

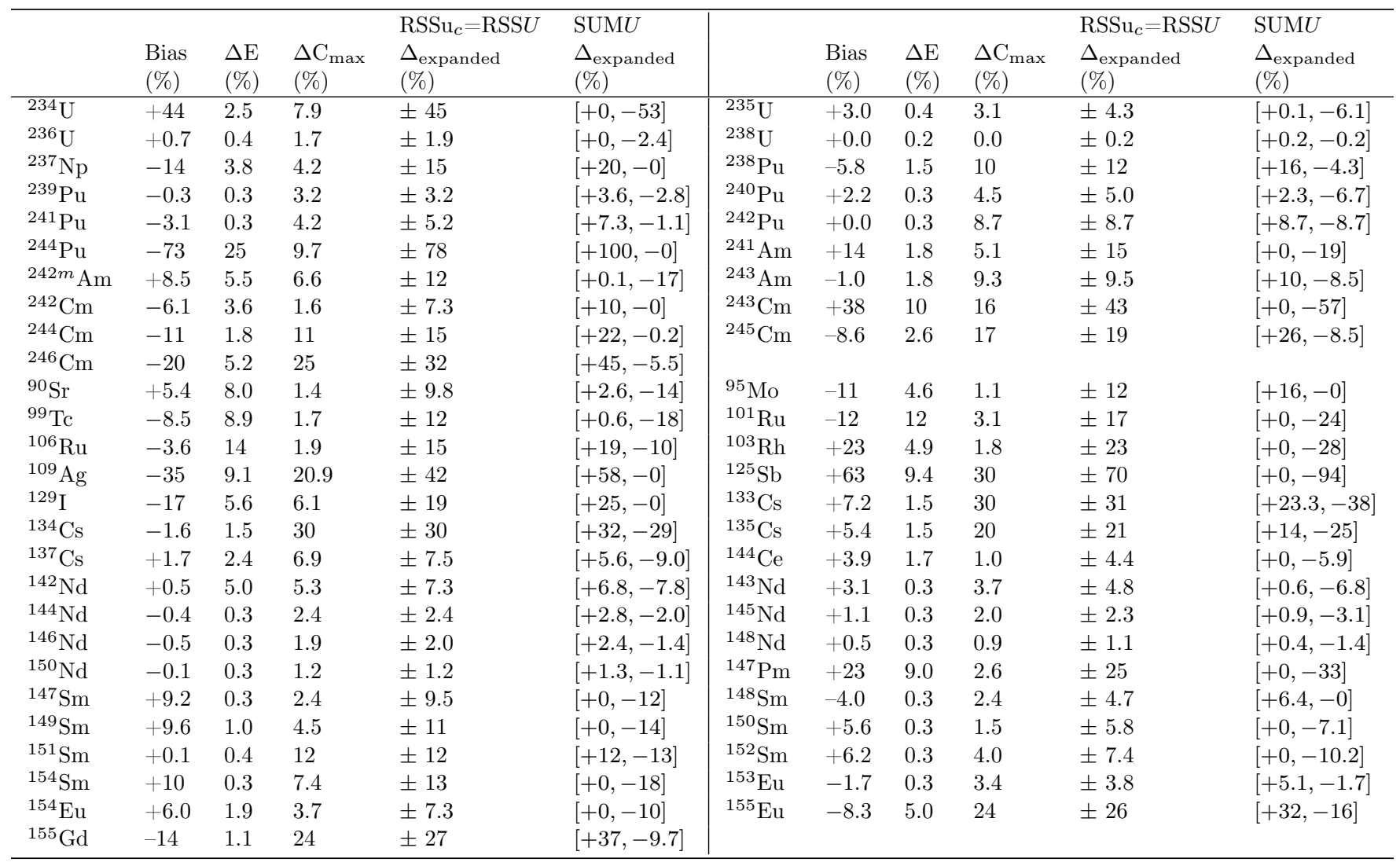


D. Rochman et al.: EPJ Nuclear Sci. Technol. 7, 14 (2021)

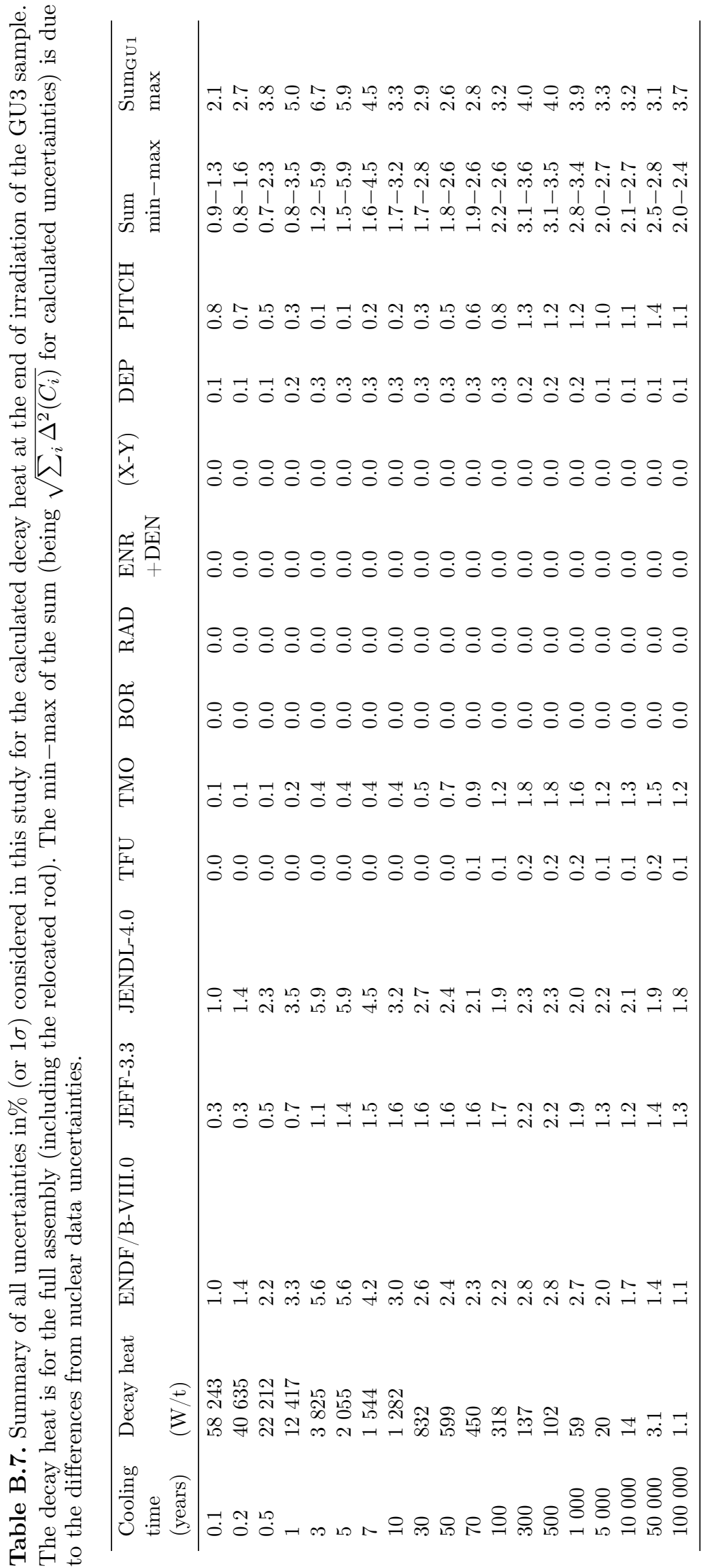




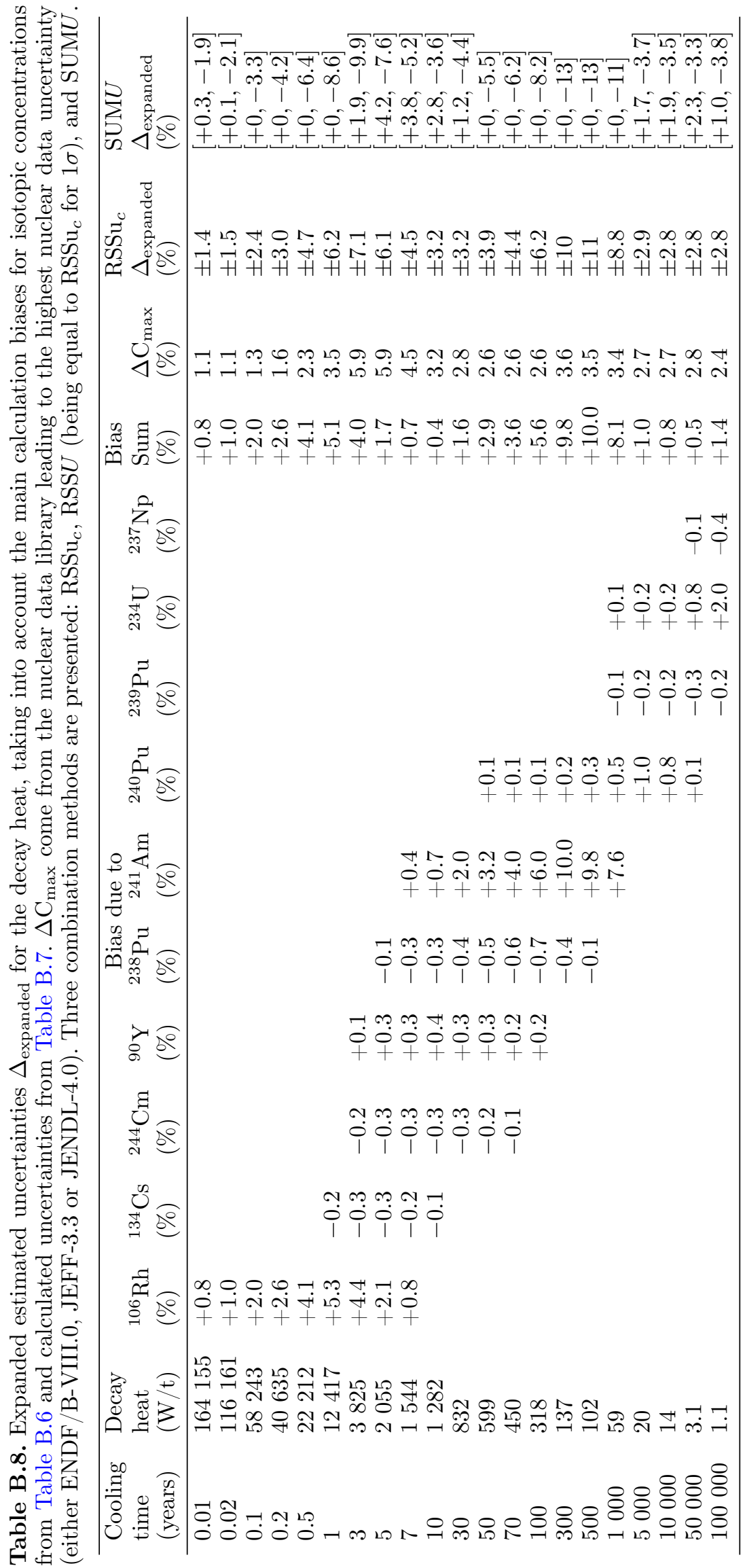

